\title{
Thermodynamic analysis and numerical optimization of the NET Power oxy-combustion cycle
}

\author{
Roberto Scaccabarozzi a,b, Manuele Gatti a , Emanuele Martelli ${ }^{\mathrm{a}, *}$ \\ ${ }^{a}$ Politecnico di Milano, Department of Energy, Via Lambruschini 4, 20156 Milano, Italy \\ ${ }^{\mathrm{b}}$ LEAP (Laboratorio Energia e Ambiente Piacenza), Via Nino Bixio 27/c, 29121 Piacenza, Italy
}

\section{ABSTRACT}

This paper presents a thorough thermodynamic analysis and optimization of the NET Power cycle (also called Allam cycle), a natural-gas-fired oxycombustion cycle featuring nearly $100 \% \mathrm{CO}_{2}$ capture level, very high net electric efficiency, and potentially near-zero emissions level. The main goals of this study are the systematic optimization of the cycle for the maximum efficiency, and the quantification of the effects of the modelling assumptions and equipment performance on the optimal cycle variables and efficiency. An Aspen Plus flow-sheet featuring accurate first-principle models of the main equipment units (including cooled turbine) and fluid properties (equation of state) has been developed. The influence of the cycle variables on the thermodynamic performance of the cycle is first assessed by means of sensitivity analyses. Then, the cycle variables, which maximize the net electric efficiency, are determined with PGS-COM, a black-box numerical optimization algorithm, linked to the simulation software. The corresponding maximum cycle efficiency is equal to $54.80 \%$ (with $100 \% \mathrm{CO}_{2}$ capture), confirming the outstanding performance of the NET Power cycle. Moreover, the optimization indicates the existence of promising combinations of the cycle variables which lead to reduced component costs (due to the lower operating pressures and temperatures) of the most critical components, without considerably affecting the net elec-tric efficiency. The analysis also indicates that the cooling medium temperature, the power consumption of the air separation unit, the effectiveness of the regenerator and the effectiveness of the turbine cooling system are the main factors influencing the cycle efficiency.

\section{Introduction}

Among the available carbon capture technologies, turbinebased oxy-combustion cycles appear to be a promising mid-term solution for the production of electricity from natural gas. The oxy-combustion technology is based on a thermodynamic cycle in which the fuel is burned in a combustor with an oxidant stream composed mainly of pure oxygen. In a conventional plant the combustion is performed using air as oxidant, but the significant

\footnotetext{
* Corresponding author.

E-mail address: emanuele.martelli@polimi.it (E. Martelli).
}

amount of nitrogen contained dilutes considerably the $\mathrm{CO}_{2}$ in flue gases. It is well known that this is one of the major drawbacks affecting the energy consumption related to $\mathrm{CO}_{2}$ Capture and Storage $[1,2]$. On the other hand, thanks to the removal of nitrogen from the oxidant, oxy-combustion cycles deal with working fluids featuring higher $\mathrm{CO}_{2}$ concentrations, which may reduce the energy intensity of $\mathrm{CO}_{2}$ separation. Nowadays, among the most interesting solutions proposed in literature for oxy-combustion cycles there are the ones based on $\mathrm{CO}_{2}$-rich and $\mathrm{H}_{2} \mathrm{O}$-rich streams as working fluids. In the former case $\mathrm{CO}_{2}$ capture is performed simply by splitting part of the main flow, while in the second case water condensation produces a stream rich in carbon dioxide, which then can be 


\section{Nomenclature}

$\begin{array}{ll}\text { Acronyms } & \\ \text { ASU } & \text { air separation unit } \\ \text { BWR-LS } & \text { Benedict-Webb-Rubin-Lee-Starling } \\ \text { CCL } & \text { CO }_{2} \text { capture level } \\ \text { CES } & \text { clean energy system } \\ \text { COT } & \text { combustor outlet temperature } \\ \text { CPSO } & \text { constrained particle swarm optimizer } \\ \text { EoS } & \text { equation of state } \\ \text { GHG } & \text { greenhouse gases } \\ \text { GSS } & \text { generating set search } \\ \text { IEA } & \text { International Energy Agency } \\ \text { IGCC } & \text { Integrated Gasification Combined Cycles } \\ \text { LHV } & \text { lower heating value } \\ \text { LT } & \text { low temperature } \\ \text { PGS-COM } & \text { particle generating set-complex algorithm } \\ \text { PR } & \text { Peng-Robinson } \\ \text { pvT } & \text { pressure-specific volume-temperature } \\ \text { SCOC-CC } & \text { Semi-Closed Oxy-Combustion Combined Cycle } \\ \text { SRK } & \text { Soave-Redlich-Kwong } \\ \text { TBC } & \text { thermal barrier coating } \\ \text { TIP } & \text { turbine inlet pressure } \\ \text { TIT } & \text { turbine inlet temperature } \\ \text { TOT } & \text { turbine outlet temperature }\end{array}$

Symbols

A surface area

c load coefficient of the turbine stage

$\begin{array}{ll}c_{p} & \text { specific heat capacity } \\ \text { EXP } & \text { adiabatic expander } \\ h & \text { heat transfer coefficient } \\ \text { HX } & \text { multi-flow heat exchanger } \\ k_{i j} & \text { binary interaction coefficient } \\ m & \text { mass flow rate } \\ M_{0} & \text { Mach number } \\ \text { MIX } & \text { mixer } \\ p & \text { pressure } \\ Q & \text { thermal power } \\ S t & \text { Stanton number } \\ T & \text { temperature } \\ u & \text { pitchline velocity } \\ U & \text { overall heat transfer coefficient } \\ v & \text { velocity } \\ V & \text { volumetric flow rate } \\ W & \text { mechanical power } \\ x & \text { mole fraction } \\ \beta & \text { pressure ratio } \\ \gamma & \text { specific heat capacities ratio } \\ \varepsilon & \text { effectiveness of the convective cooling system } \\ \eta & \text { efficiency } \\ \theta & \text { defined as }(\gamma-1) / \gamma\end{array}$

easily captured via partial condensation (however in both cases a further purification step may be required depending on $\mathrm{CO}_{2}$ purity specifications).

Over the last 30 years, different layouts have been proposed, including the Semi-Closed Oxy-Combustion Combined Cycle (SCOC-CC) [3], the MATIANT cycle [4], the NET Power cycle [5,6], the Graz cycle [7] and the CES cycle [8]. The SCOC-CC, MATIANT and NET Power cycles use $\mathrm{CO}_{2}$ as diluent to limit both the combustion and turbine inlet temperatures, while the Graz and the CES cycles use $\mathrm{H}_{2} \mathrm{O}$.

The basic idea of the SCOC-CC cycle is to use pure oxygen provided by a cryogenic air separation unit (ASU) as oxidant in the combustor of a gas turbine combined cycle, and to recycle a fraction of the generated $\mathrm{CO}_{2}$ so as to moderate the turbine inlet temperature. Since the plant does not feature any gas stack, all the generated $\mathrm{CO}_{2}$ (as well as pollutants) is captured $\left(\mathrm{CO}_{2}\right.$ capture level $=100 \%$ ). For the SCOC-CC cycle, Chiesa and Lozza [9] esti-mated, in an Integrated Gasification Combined Cycles (IGCC) con-figuration, a net electric efficiency of 39\%, while Lozza et al. [10] calculated a net electric efficiency equal to $46.17 \%$. Riethmann et al. [11] developed a supercharged SCOC process reaching a net plant efficiency up to $50 \%$, as a result of several sensitivity analyses covering different ranges of hot gas temperatures, pressure ratios and supercharge factors.

The MATIANT cycle consists of a combination of a supercritical $\mathrm{CO}_{2}$ cycle and a higher temperature regenerative reheated gas cycle (using a $\mathrm{CO}_{2}$-rich working fluid). Similarly to the SCOC-CC cycle, all the generated $\mathrm{CO}_{2}$ is captured. Yantovski et al. [12] pro-posed a MATIANT cycle (named "quasicombined COOPERATE cycle") reaching an electric efficiency of 52\%. Then Yantovski [13] compared it against conventional power plants from a technoeconomic point of view, estimating, for the former, an electric efficiency of $54.3 \%$ for the case with nearly zero $\mathrm{CO}_{2}$ emissions. Mathieu and Nihart [14] presented a sensitivity analysis of the MATIANT cycle showing the effects of different parameters on the plant net electric efficiency. They reported an overall efficiency of $44.2 \%$ for the best case.

Allam et al. [15] developed a highly regenerative supercritical cycle called "NET Power cycle" or "Allam cycle". The turbine inlet temperature is controlled by recycling a large amount of supercritical $\mathrm{CO}_{2}$ to the combustor while heat recovery of the turbine exhaust gases is performed using a multi-flow heat exchanger (the regenerator). A detailed description of the cycle is reported in Section 2. In [16] the developers estimated a cycle efficiency for natural gas combustion of $59 \%$ for the single combustor scheme (without reheat) and about $57.5 \%$ for the double combustor scheme (with reheat).

An alternative option is the Graz Cycle, which integrates a high temperature Brayton cycle (made by a compressor a combustor and cooled turbine handling a mixture of $\mathrm{H}_{2} \mathrm{O}$ and $\mathrm{CO}_{2}$ as working fluid), with a low temperature steam cycle (made by a high pres-sure turbine, a low pressure turbine, a condenser, and a Heat Recovery Steam Generator). Starting from the original scheme pub-lished in [7], different improvements have been proposed over the last twenty years by the researchers of the Graz University of Technology. For instance, Sanz et al. [17] proposed the "S-Graz" cycle featuring a higher steam content compared to the original layout thanks to the adoption of different cycle parameters. A net electric efficiency of $57.7 \%$ was assessed by the authors. Later, Jericha et al. [18] developed and designed a new scheme with condensation of the $\mathrm{H}_{2} \mathrm{O}-\mathrm{CO}_{2}$ mixture at atmospheric pressure which allows to improve the heat transfer process in the condenser. Jericha et al. [18] assessed an overall efficiency of about 54\%.

The CES cycle is essentially an internal combustion steam cycle using the injection of steam and liquid water in the combustor to moderate the firing temperature. Pure oxygen is used as oxygen and natural gas (or other fuels) as fuel. At the exit of the combustor, the mixture of $\mathrm{H}_{2} \mathrm{O}$ and $\mathrm{CO}_{2}$ expands in a turbine (eventually with reheat) and then it is cooled down in a water condenser. Anderson et al. [19] discussed the technological evolution of the CES cycle, by 
envisaging a net electric efficiency in the range between $45 \%$ and $55 \%$ for natural gas fired plants. Hustad et al. [20] proposed an improved version of the CES cycle obtaining a net cycle efficiency of $45 \%$. In [21] a further improvement of the cycle is presented, called Supercritical CES, employing a combustor operating at supercritical steam conditions.

Complete reviews of the available oxy-combustion cycle options can be found in the recent report [21] published by the International Energy Agency (IEA) Green House Gas program and co-authored by AMEC-Foster Wheeler and Politecnico di Milano. In order to make a fair comparison between the alternative options, each cycle has been modelled and its thermodynamic and economic performances have been estimated on a common design basis. The results of the thermodynamic calculations indi-cate a net electric efficiency of $49.3 \%$ for the SCOC-CC cycle, $55.1 \%$ for the NET Power cycle, $49.2 \%$ for the S-Graz cycle and $48.9 \%$ for the supercritical CES. The economic analysis shows that the NET Power cycle has the lowest Cost of Electricity (COE), equal to 88.3€/MWh, and the other cycles are in the range 93-95€/MWh.

Thus, according to [21], the NET Power cycle is the most promising option both in terms of efficiency and economics. The main advantages of this cycle are (1) the limited total specific plant cost $(1560 € / \mathrm{kW})$, the lowest value among the above considered oxy-combustion cycles, and (2) the very high net electric efficiency (which limits the impact of the fuel cost on the COE). The attractiveness of the cycle is also due to its simplicity and limited number of components compared to other fossil-fuel systems with $\mathrm{CO}_{2}$ capture. Given the cost and efficiency values claimed by the cycle developers, the NET Power cycle has attracted the attention of several research institutes as well as companies and policy makers. For instance, the NET Power company, in association with CB\&I, Toshiba, Exelon, and Shaw Group is developing a $50 \mathrm{MW}_{\text {th }}$ demonstration plant in Texas (U.S.) [22]. Also the UK Department of Energy and Climate Change has supported further R\&D activities on this cycle.

Despite its promising thermodynamic and economic performance indexes, only a few publications, most of them written by the developers of the cycle, are available in the public literature. Besides, a thorough thermodynamic analysis of the cycle and its systematic optimization by means of optimization algorithms are still lacking.

The objectives of this study are:

(i) Determine the optimal cycle variables and the corresponding maximum electric efficiency achievable by the NET Power cycle.

(ii) Evaluate the sensitivity of the cycle efficiency to the performance of the equipment units, to the main design assumptions, and to the modelling assumptions.

(iii) Explore promising combinations of the cycle variables which allow to reduce the costs (and/or research and development efforts) of the equipment units while maintaining close-tooptimal efficiency.

To these purposes, this work performs an in-depth thermodynamic analysis of the NET Power cycle aimed at determining the effect of each cycle variable, modelling assumption and equipment performance on the net electric efficiency and power output of the cycle. The analysis is based on accurate models of the equipment units built in Aspen Plus. Due to the need of assessing the performance of a cooled turbine expanding a real gas mixture (and not an ideal gas mixture as in conventional gas turbines), an improved version of El Masri's continuous expansion model [23] was specifically developed.

\section{NET Power cycle}

The NET Power cycle scheme, as first presented by Allam et al. in 2011 [5], is represented in Fig. 1.

Almost pure oxygen (99.5\% purity, molar basis) pressurized at 120 bar is supplied by a cryogenic ASU (stream $\mathrm{O}_{2}$ ) and then it is mixed with a stream of recycled $\mathrm{CO}_{2}$ (stream RE-OX), preheated to approximately $720{ }^{\circ} \mathrm{C}$ in the regenerator and sent to the combustor. Oxygen is mixed with $\mathrm{CO}_{2}$ before being preheated in the regenerator for safety reasons. The combustor operates between 200 bar and 400 bar and the firing temperature is moderated by injecting a large recycle stream of $\mathrm{CO}_{2}$ (stream RE-4). Hot combustion gases at temperatures above $1100{ }^{\circ} \mathrm{C}$ enter a cooled turbine featuring a limited expansion pressure ratio, between 6 and 12 . Flue gases at approximately $700-800{ }^{\circ} \mathrm{C}$ and $30-60$ bar enter a multi-flow heat exchanger (the regenerator) which allows to efficiently recover the available heat by preheating the recycle streams (streams RE-3, OX-2) as well as the turbine cooling flows (stream CF-1). At the exit of the regenerator, the exhaust stream is cooled close to ambient temperature in a cooler which con-denses and separates the water. The remaining stream (stream FG-4) is essentially pure $\mathrm{CO}_{2}$ in the gas phase. Part of this stream is separated and sent to $\mathrm{CO}_{2}$ purification, compression and storage, while the majority (stream RE-1, around 95\% of stream FG-4) is compressed and recycled back to the combustor as temperature moderator. The intercooled compressor pressurizes the recycle stream to about 80 bar and the aftercooler takes it to near ambient temperature. Since these conditions are supercritical (dense phase $\mathrm{CO}_{2}$ ) and correspond to a very high density of about $700 \mathrm{~kg} / \mathrm{m}^{3}$, the compression from 80 bar to the combustor pressure is performed with multi-stage centrifugal pumps. A stream of $\mathrm{CO}_{2}$ at 120 bar (stream RE-OX) is extracted and mixed with the pressurized $\mathrm{O}_{2}$ provided by the ASU.

The operating points for the NET Power cycle designed by Allam et al. [6] are shown in the Pressure-Enthalpy diagram reported in Fig. 2. To reach a high overall net electric efficiency, the cycle minimizes the fuel input by heating up the recycled streams and oxygen within the regenerator, while recovering heat from the turbine outlet stream and the ASU compression section. However, it must be noted that, as shown in Fig. 2, there is a lack of heat: the heat released by the exhaust low pressure stream, B-C in the diagram, is lower than the one required by the high pressure recycle, F-G. The cause of this difference (which is the opposite situation com-pared to conventional regenerative gas turbines) is that the specific constant pressure heat capacity of $\mathrm{CO}_{2}$ increases with pressure, especially at low temperatures [16].

Part of the heat required supplied by the condensation of water in the turbine exhaust gas. This phenomenon occurs within the regenerator when the temperature of stream B-C goes below $150^{\circ}$ C. Notice that this heat cannot be seen in Fig. 2 because, for the sake of simplicity, that diagram considers pure $\mathrm{CO}_{2}$ as working fluid. Another fraction of the heat deficit is covered by the air cooler of the cryogenic air separation unit (ASU): the main air com-pressor can make available hot air at $270{ }^{\circ} \mathrm{C}$, if it is not intercooled. According to the cycle developers [15], even though such an arrangement increases the power consumption of the ASU main air compressor, the overall effect on the cycle efficiency is positive. Heat is transferred from the ASU to the regenerator by a loop of heat transfer fluid, such as thermal oil.

The turbine is not an off-the-shelf-equipment but needs to be developed ad hoc for this cycle. The critical features of the turbine are:

1. The inlet pressure is rather high, imposing the adoption of an ad hoc shell. 


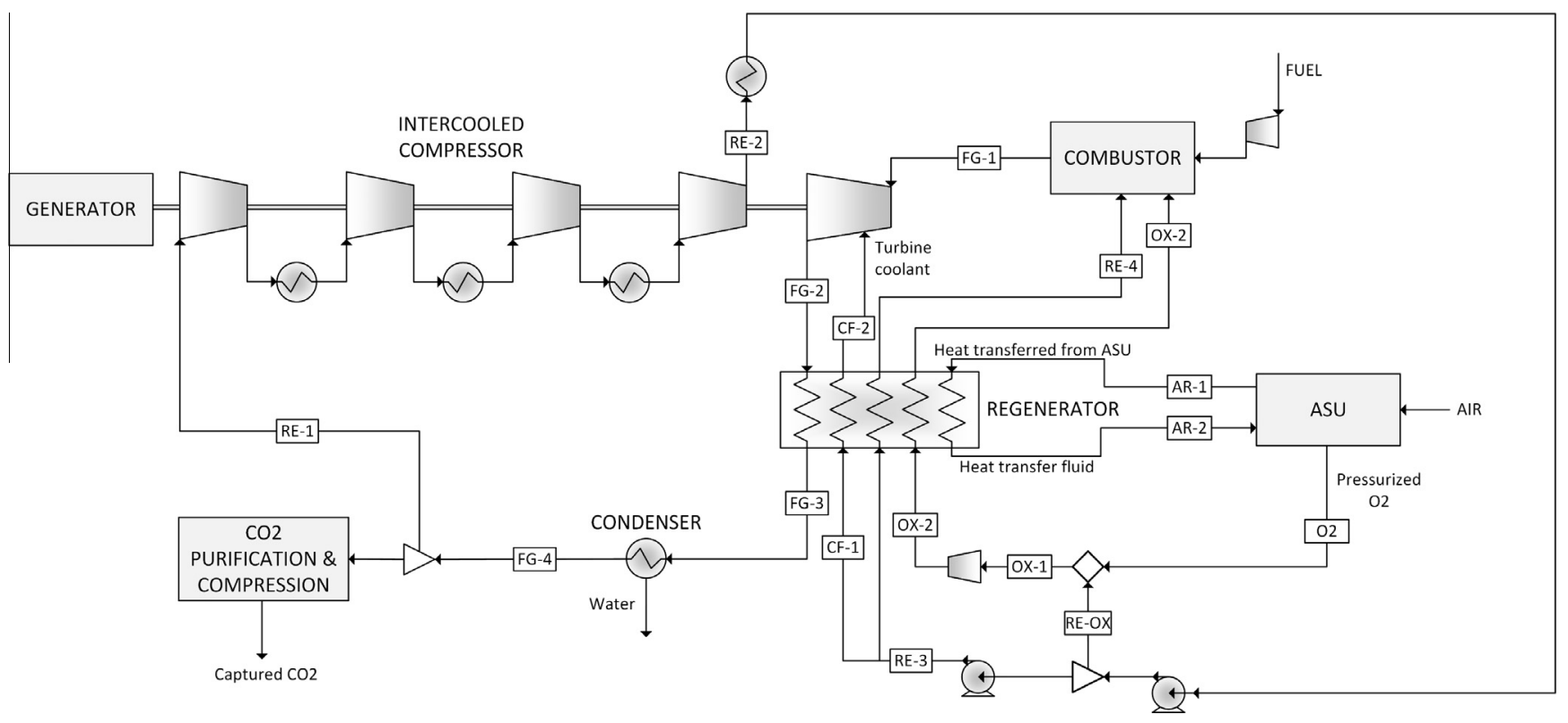

Fig. 1. Scheme of the analysed NET Power cycle.

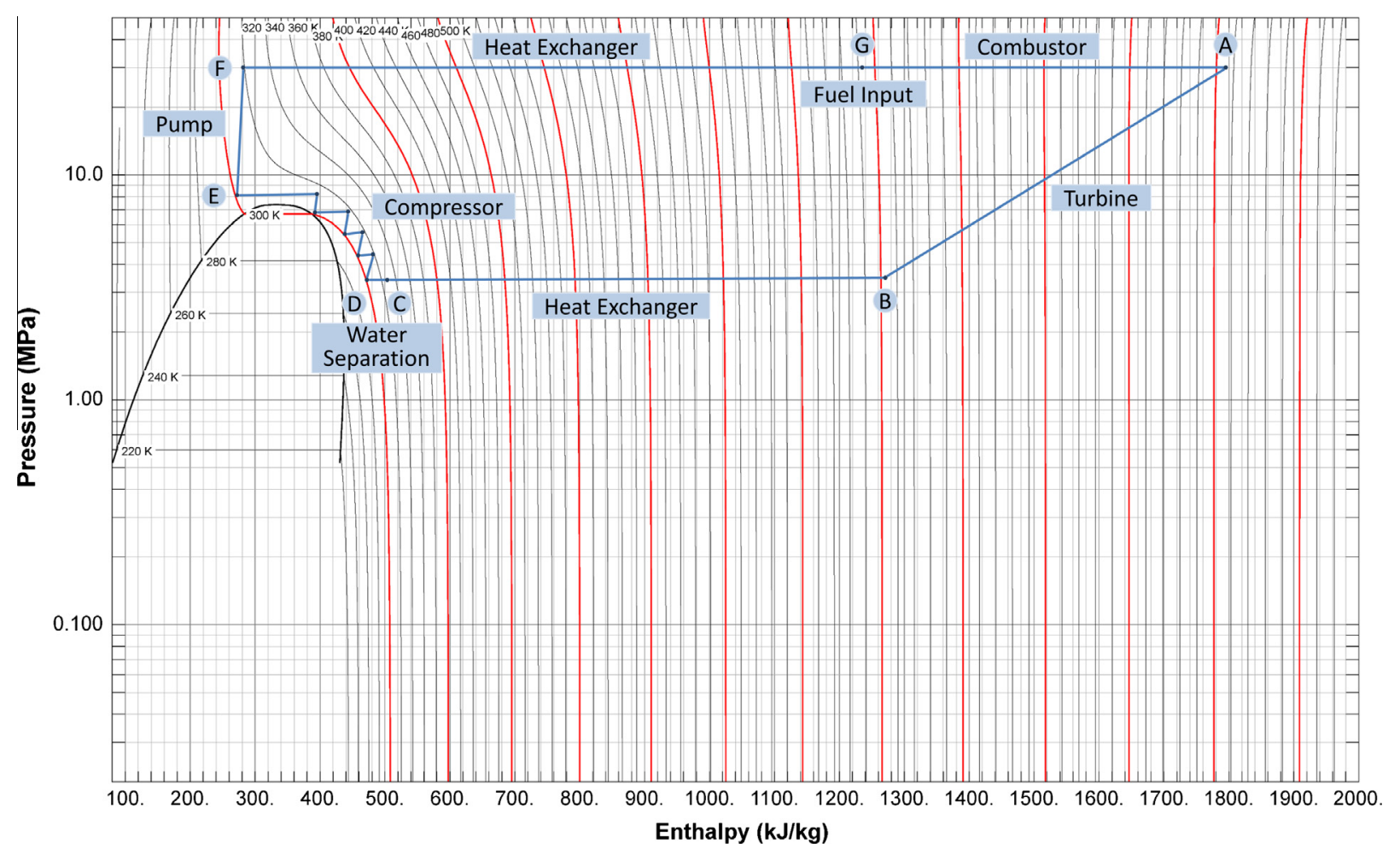

Fig. 2. Pressure-enthalpy diagram of the NET Power cycle assuming pure carbon dioxide as working fluid.

2. Blades and shell need to be cooled because of the relatively high turbine inlet temperature.

3. The working fluid is unconventional.

According to the cycle developers [15], despite the challenging issue, this component may use well-known, well proven technologies without the requirement of large research and development efforts. To the best of our knowledge, such a turbine design has not been tested yet [24]. However, Ref. [15] reports details of the mechanical design of the turbine, including material specifications: the outer casing and the first inner casing, thanks to the cooling system, can be made by $\mathrm{CrMoV}$ and the second inner casing is designed using Ni-based materials, where temperature is above $700{ }^{\circ} \mathrm{C}$. As for the rotor, Ni-based materials are used for the central portion and $\mathrm{CrMoV}$ is used for the end of the rotor. As for blade cooling, NET Power proposes to use a classic open-circuit blade cooling system. Blades are protected by Thermal Barrier Coating and cooled by convection [15]. According to the cycle developers, film cooling, that is used in today's gas turbines, is not necessary because the turbine inlet temperature is not extremely high and 
the heat transfer coefficient of the cooling flow (almost pure $\mathrm{CO}_{2}$ ) is sufficiently high compared to that of the main stream.

As for the combustor, an ad hoc diffusion flame burner is used. Pre-mixed combustor, used in today's gas turbines to mitigate the production of $\mathrm{NO}_{X}$, cannot be used as the pre-mixed flame would be instable at those high pressures causing combustion instability [25]. Thus, diffusion-flame combustor has been specifically devel-oped and tested by Toshiba Corporation. The developers state that the combustor was successfully tested [26,27]. It is worth men-tioning that, as reported by [28], there is an optimal oxygen/dilu-ent ratio in the oxidizer of oxy-combustion gas turbines both to ensure flame stability and to avoid excessive flame temperature and dissociation reactions. In this study we assumed that the oxy-gen/diluent ratio of $15.5 \%$ indicated in [21] is suitable.

The oxygen required for the combustion is provided by a standard cryogenic ASU. The oxygen stream cannot be supplied at high pressure directly to the combustor because the maximum allowed pressure of the main heat exchanger of the cryogenic unit is limited to about 120 bar [29]. Therefore, the oxygen flow is mixed with part of the supercritical recycled $\mathrm{CO}_{2}$ so as to have oxygen concentrations in the range of 10-30\% (molar basis), and then compressed to the required pressure by a dedicated $\mathrm{O}_{2} / \mathrm{CO}_{2}$ dense phase compressor. Before entering the combustor, the oxidant mixture is preheated in the regenerator. It is worth noting that the oxygen purity recommended by the cycle developers is $99.5 \%$ (molar basis), a rather high value compared to the ones typically used in Integrated Gasification Combined Cycles (IGCC) [30], but commonly adopted in chemical plants like gasification plants for the synthesis of Fischer-Tropsch fuels or Substitute Natural Gas [31]. The reason behind this choice is the minimization of the com-bined consumption of the ASU (increasing with the $\mathrm{O}_{2}$ purity due to the more severe oxygen/argon distillation), the carbon dioxide purification unit and the recycle gas re-compressors (decreasing with the $\mathrm{O}_{2}$ purity due to the reduction of the non-condensable species mixed with $\mathrm{CO}_{2}$ ). The comparison between the two cases employing $99.5 \%$ vs. $97 \%$ oxygen purity reported in [21] shows that the maximum cycle efficiency is achieved with the highest purity.

In addition to the turbine and combustor, the NET Power cycle includes another unconventional piece of equipment, i.e. the regenerator of the recycled stream. The following features make its design and manufacturing quite challenging (and certainly costly):

1. It has to handle multiple hot and cold streams: exhaust flow discharged by the turbine, the $\mathrm{CO}_{2}$-rich recycled stream, the oxidant, the turbine cooling flow and the heat transfer fluid that transfers heat from the ASU.

2. It has to withstand high temperatures (metal temperatures up to $700-750{ }^{\circ} \mathrm{C}$ ) and large pressure differences (200-300 bar) between the hot and cold streams.

3. Its heat transfer area is extremely large as it has to transfer about 2.9 MW per each MW of net electric power (e.g., $1.45 \mathrm{GW}$ in a plant generating $500 \mathrm{MW}$ of net electric power) with very small temperature difference (see Section 6.3).

4. The hot stream is corrosive since it contains $\mathrm{CO}_{2}$ and condensing water.

\section{Models and assumptions}

The model of the NET Power cycle was developed in Aspen Plus V8.4 [32], a commercial sequential modular process simulation software licensed by Aspen Tech. Among the cycle components (compressors, pumps, expander, heat exchangers, etc.), the turbine and the regenerator required the definition of ad hoc models. The other equipment units were modelled with the blocks readily available in Aspen Plus.

\subsection{Turbine model}

To estimate the performance of the NET Power cycle (power output, turbine outlet temperature and mass flow rates of the cooling flows) it was necessary to develop a cooled turbine model capable of handling real gas mixtures. This is necessary since both commercially available gas turbine simulation codes (e.g., GT PRO [33]) and proprietary codes (e.g., "GS" simulation code devel-oped by Politecnico di Milano [34]) have been developed so far to model only standard gas turbines and, as a consequence, they assume that the working fluid is an ideal mixture of ideal gas spe-cies. Hence, the expander model implemented should have the fol-lowing features: (i) the possibility to include suitable Equation of States (i.e., Peng-Robinson and other cubic models) to reproduce more accurately the fluid behaviour; (ii) it should have only a few calibration parameters, without requiring any geometrical information of the stages, since such details are still undisclosed. Among the models reported in literature, the cooled expansion model proposed by El-Masri [23] seems ideally suited because it has few input parameters, it does not need any assumption on stages geometry and it can be adjusted to deal with real gases. On the other hand, it can deal only with ideal gases and does not take into account the total pressure losses caused by the injection of the cooling flows in the mainstream [35]. For this reason, it was necessary to adapt El-Masri's model as described in the following.

\subsubsection{El-Masri's continuous expansion model}

The model by El-Masri is a "continuous expansion" model, meaning that the turbine is treated as an expander whose walls continuously extract work, without distinguishing between stages, stators and rotors. The expansion is divided into infinitesimal steps capable to model the extraction of mechanical power $(d W)$, thermal power from the walls $(d Q)$, and the injection of coolant $(\mathrm{dm})$ into the expanding stream. The basic assumption is that the specific power flux $(W)$ per unit of wall surface area $\left(A_{w}\right)$ is constant along the expansion path and equal to the average value of the whole turbine:

$\frac{d W}{d A_{w}}=$ const $=\frac{W}{A_{w}}$.

Since $W$ can be written in terms of the load coefficient of the turbine stages $(c)$ and the pitchline velocity $(u)$ according to Eq. (2), where $m$ is the mass flow rate,

$W=m c u^{2}$,

and the thermal power $d Q$ exchanged between the hot flue gases and the cooling flows through the step walls $\left(d A_{w}\right)$ can be written as a function of the heat transfer coefficient $(h)$ and the temperature difference between the flue gases $(T)$ and the walls $\left(T_{W}\right)$,

$d Q=h\left(T-T_{w}\right) d A_{w}$,

then the heat absorbed by the cooling flows $d Q$ can be directly related to the power output $d W$ :

$d Q=\frac{S t\left(A_{w} / A_{g}\right)}{c(\gamma-1) M_{0}^{2}}\left(\frac{T}{T_{0}}-\frac{T_{w}}{T_{0}}\right) d W$,

where $S t$ is the average Stanton number of the turbine stages, $A_{g}$ is the cross-sectional area of the main gas flow, $\gamma$ is the specific heat capacity ratio, and $M_{0}$ is the turbine Mach number ( $u$ divided by the velocity of sound at ambient temperature $T_{0}$ ).

Moreover, also the mass flow rate of injected coolant can be related to $d W$ because the following relations hold

$d Q=c_{p}\left(T_{c_{-} \text {out }}-T_{c_{-} \text {in }}\right) d m$,

$\left(T_{c_{-} \text {out }}-T_{\text {c_in }}\right)=\varepsilon\left(T_{w}-T_{c_{-} \text {in }}\right)$, 
where $c_{p}$ is the specific heat capacity at constant pressure of the cooling flow, $T_{c_{-} \text {in }}$ and $T_{c_{-} \text {out }}$ are the temperatures of the cooling flow at inlet and outlet of the blade, and $\varepsilon$ is the effectiveness of the convective cooling system. Combining Eqs. (4) and (6), the following Eq. (7) (providing the mass flow rate of injected coolant as a func-tion of the extracted power) can be obtained:

$d m=\frac{S t\left(A_{w} / A_{g}\right)}{c(\gamma-1) M_{0}^{2} c_{p} \varepsilon}\left(\frac{T}{T_{0}}-\frac{T_{w}}{T_{0}}\right) \frac{1}{\left(T_{w}-T_{c_{-} \text {in }}\right)} d W$.

Since El-Masri proposed the model for conventional natural gas fired gas turbines, by introducing the assumption of perfect gas he could integrate analytically the ordinary differential equation resulting from Eq. (7).

\subsubsection{Improved continuous expansion model}

In order to adapt El-Masri's model to the purposes of this study, the following modifications have been made:

1. The number of expansion steps cannot be infinite as in the original version because, if the gas behaviour is not modelled with the perfect gas assumption, Eq. (7) cannot be analytically integrated. The expansion needs to be divided into a finite number of (small) steps, and the overall set of equations needs to be solved by means of a numerical algorithm.

2. In order to improve the accuracy of the model, it is necessary to include a correlation, which assesses the total pressure losses caused each time cooling flows and mainstream are mixed.

A scheme of the revised model is represented in Fig. 3.

Model variables and parameters involve total (stagnation) pressures $(p)$, total (stagnation) temperatures $(T)$, mass flow rates $(m)$, volumetric flow rates $(V)$, pressure ratios $(\beta)$ and mechanical power extracted by the expanders $(W)$. Static temperatures and gas velocities are not directly considered in the model. The expansion is divided into $N+1$ steps, where the first $N$ steps are cooled, while the last one $(N+1)$ is adiabatic and corresponds to the uncooled section of the turbine. Each cooled step is made of an adiabatic expander (EXP-i), a mixer (MIX-i, mixing the mainstream Oi with the cooling flow $C i$ ideally associated to the EXP-i), and a valve (VALVE-i). $N$ is set to a reasonably large number (e.g., 15). All the expanders have the same isentropic efficiency. The first $N$ steps have the same pressure ratio $\beta$ which is iteratively adjusted so as to have $T_{I_{-} N+1}=T_{w}$ (flue gases temperature must be equal to $T_{w}$ at the inlet of the uncooled turbine section). Of course, the pressure ratio of the uncooled turbine section $\left(\beta_{N+1}\right)$ is a dependent variable as it is automatically set by $\beta$ and the turbine outlet pressure ( $p_{\text {OUT }}$ ). The mass flow rate $m_{c i}$ of each cooling stream is computed according to Eq. (8) which has been derived from Eq. (7),

$m_{C i}=K_{1} \frac{\left(T_{I i}-T_{w}\right)}{\left(T_{w}-T_{C i}\right)} W_{E X P-i}$,

where
$K_{1}=\frac{S t\left(A_{w} / A_{g}\right)}{T_{0} c(\gamma-1) M_{0}^{2} c_{p} \varepsilon}$

and $W_{E X P-i}$ denotes the power extracted from the $i$-th expander and $T_{I i}$ is the temperature at the inlet of EXP-i. According to Eq. (8), the mass flow rate of the cooling flows is directly proportional to the difference $T_{I i}-T_{w}$ (hence, the higher is $T_{I i}$, the larger is the coolant flow rate) and inversely proportional to $T_{w}-T_{C i}$ (hence, the closer is $T_{C i}$ to $T_{W}$, and the larger is the coolant flow rate).

It is worth noting that the value of $K_{1}$ depends on the following features and performance indexes of the turbine stages:

- Stanton number on the flue gas side, which, in turn, depends on the flue gas composition, thermodynamic conditions (pressure and temperature), and velocity.

- Ratio $A_{w} / A_{g}$.

- Loading factor of the stages $c$.

- Mach number of the stages $M_{0}$ (i.e., pitchline velocity of rotor).

- Technology (convective cooling, film cooling, Thermal Barrier Coating, etc.) and effectiveness of the cooling system.

Thus, $K_{1}$ is a critical performance parameter of the turbine and requires a careful calibration.

Within each stage, mainstream and coolant are mixed at the outlet of each expander. This causes a decrease of total temperature and total pressure (cooling flows are discharged into the mainstream at lower velocities and with different direction and this causes considerable fluid-dynamic losses [35,36] which leads to a loss of total pressure). The basic idea of this model is to isolate the two effects: first determine the decrease of total temperature at constant pressure and velocity with the mixer (MIX-i), then compute the loss of pressure at constant total enthalpy with the valve (VALVE-i). The decrease of temperature can be easily computed by applying the energy balance equation to the mixer (MIX-i). Instead, a simplified model is needed to determine the loss of total pressure due to the mixing of coolant and mainstream. Such model must be capable of providing a reasonably accurate assessment of the pressure losses without detailed information about the turbine geometry. A simple model can be derived from the one-dimensional conservation of linear momentum along the mainstream direction and the following assumptions:

1. Coolant is discharged at negligible velocity (negligible compared to that of the mainstream).

2 . In the mixing zone, coolant is accelerated to the mainstream velocity $\left(v_{m}\right)$.

3. The difference of total pressure across the mixing zone $\left(p_{O i}\right.$ $\left.-p_{I i+1}\right)$ is approximately in direct proportion to the difference of static pressure because (i) across the valve the total temperatures are approximately constant, $T_{H i} \approx T_{I i+1}$ (even for a real gas), as the pressure drop is expected to be limited to a few bars (or fractions of bar); (ii) coolant is accelerated to the same velocity as the mainstream.

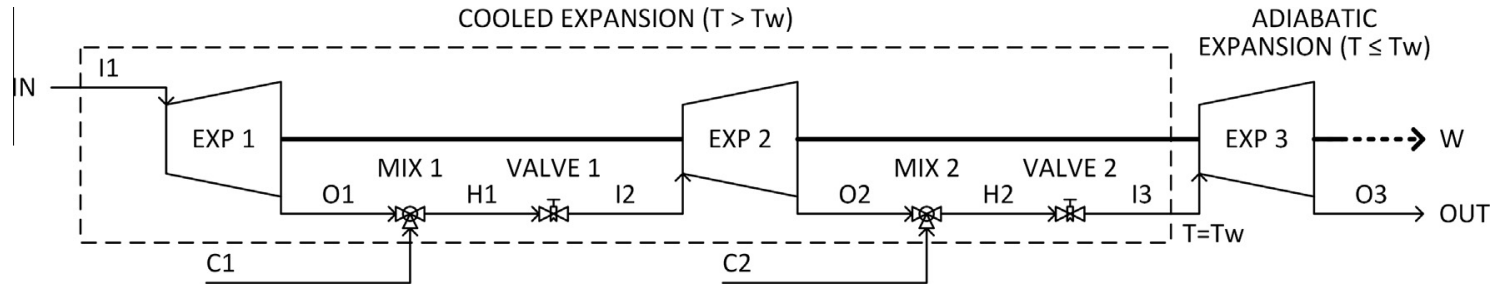

Fig. 3. Model of the improved continuous expansion model with $N$ (number of cooled expansion steps) equal to 2 . 
On the basis of assumptions (1-3) and the linear momentum equation, it is possible to derive Eq. (10),

$p_{O i}-p_{I i+1}=\left(\frac{T_{H}}{T_{H}-v_{m}^{2} / 2 C_{p}}\right)^{1 / \theta} \frac{m_{C i} v_{m}}{A_{g \alpha}}$,

which relates the pressure loss to the mass flow rate of cooling flow, its final velocity (as it is accelerated from zero to $v_{m}$ ) and the projection of cross-sectional area of the machine along the mainstream velocity $\left(A_{g \alpha}\right)$. Since determining $v_{m}$ and $A_{g \alpha}$ at each step requires a set of geometrical information about the stages which are not available for the NET Power turbine, it was decided to:

1. Relate $A_{g \alpha}$ to the volumetric flow rate of the inlet stream $H_{i}\left(V_{H i}\right)$. 2. Assume that the term $\left(\frac{T_{H}}{T_{H}-V_{m}^{2} / 2 C_{p}}\right)^{1 / \theta}$ is constant across the expansion as it can be related to the flow Mach number $\left(v_{m} / \sqrt{\gamma R T_{H}}\right)$, which is kept approximately constant along the expansion.

3. Group all the parameters into a single calibration parameter $K_{2}$ and, in order to take into account the possible variations of $v_{m}$ and $A_{g \alpha}$ along the expansion steps, introduce an exponential parameter $\left(K_{3}\right)$ which is expected to be close to one.

The resulting correlation is given in Eq. (11):

$p_{O i}-p_{I i+1}=K_{2}\left(\frac{m_{C i}}{V_{H i}}\right)^{K 3}$.

The model including Eqs. (8) and (11) as well as the energy and mass balance equations of each piece of equipment of Fig. 3 has been implemented in Aspen Plus. The fluid properties have been modelled with the Peng-Robinson Equation of State which, according to [37], is suitable for the considered range of pressures and temperatures. Indeed, the turbine inlet conditions (combustor outlet stream and cooling flows) are sufficiently far from the critical point and the saturation curve. The model equations have been solved with the default sequential flowsheet solver.

Table 1

Model calibration results relative to the reference turbine.

\begin{tabular}{|c|c|c|c|}
\hline Output & $\begin{array}{l}\text { Proposed } \\
\text { model }\end{array}$ & $\begin{array}{l}\text { GS model } \\
{[36]}\end{array}$ & $\begin{array}{l}\text { Error } \\
(\%)\end{array}$ \\
\hline Net mechanical power (MW) & 588.44 & 582.2 & 1.07 \\
\hline $\begin{array}{l}\text { Turbine outlet temperature } \\
\quad\left({ }^{\circ} \mathrm{C}\right)\end{array}$ & 563.9 & 567.1 & -0.56 \\
\hline Exhaust flow rate $(\mathrm{kg} / \mathrm{s})$ & 803.5 & 798.17 & 0.67 \\
\hline Coolant flow rate $(\mathrm{kg} / \mathrm{s})$ & 123.4 & 118.1 & 4.5 \\
\hline
\end{tabular}

The equations obtained contain the three parameters $K_{1}, K_{2}$ and $K_{3}$ which need careful calibration as they depend not only on the effectiveness of the cooling system and the design of the stages but also on the fluid composition. For this reason, the three param-eters were calibrated using as reference a cooled turbine, accu-rately modelled with the GS software [34,36], expanding a similar gas mixture in the pressure range $45-1$ bar and tempera-ture range $1250-565^{\circ} \mathrm{C}$ where it can be accurately modelled as an ideal gas. In particular, the reference turbine features the tech-nology level of a typical "frame F" gas turbine with a maximum allowed metal temperature of $860^{\circ} \mathrm{C}$, thermal barrier coating and film cooling on the blades of the first stage. It is worth noting that, compared to [15], also film cooling is employed in our analysis so as not to penalize the turbine performance and evaluate the effi-ciency achievable with the best available technologies. The calibra-tion procedure specifically developed by Chiesa and Macchi [36] for gas turbines was applied to determine the values of the three constants $K_{1}, K_{2}$ and $K_{3}$. The results are reported in Table 1 and the calibrated values of the three constant are respectively $K_{1}=1.141 \mathrm{E}-06 \mathrm{~kg} / \mathrm{kJ}$, $K_{2}=0.750 \mathrm{~Pa}(\mathrm{~m} / \mathrm{kg})$ and $K_{3}=1.032$.

\subsection{Regenerator model}

As described by Guo [38], the design and performance of supercritical $\mathrm{CO}_{2}$ regenerators are considerably affected by the sudden change of thermodynamic properties across the critical point of the fluid. This consideration is valid also for $\mathrm{CO}_{2}$-rich mixtures handled by the NET Power regenerator. As a result, the regenerator cannot be simply modelled as a multi-flow heat exchanger because of the large variation of the specific heat capacity of the fluids and the condensation of water below the dew-point of the exhaust stream. Moreover, hot and cold streams enter and exit the regenerator at different temperatures. For these three reasons, multiple pinch-points (which actually limit the heat recovery process) may exist in the regenerator, as shown in the Temperature-Enthalpy (thermal power) diagram reported in Fig. 4. There are three pinchpoints, one on the cold side, a second one on the hot side and third one in correspondence to the dew-point of the tur-bine exhaust stream.

Thus, the regenerator model must be capable of handling multiple streams, multiple pinch-points, and fluids with variable heat capacity. For the latter issue, classic heat integration approaches, such as Pinch-Analysis techniques [39], based on the assumption of constant heat capacity of the streams are not directly applicable. In this work, the regenerator model reported in Fig. 5 is used.

The regenerator is modelled as two multi-flow heat exchangers, $H X 1$ and $H X 2$, (which can properly deal with streams featuring variable heat capacity) connected in series. The temperatures of

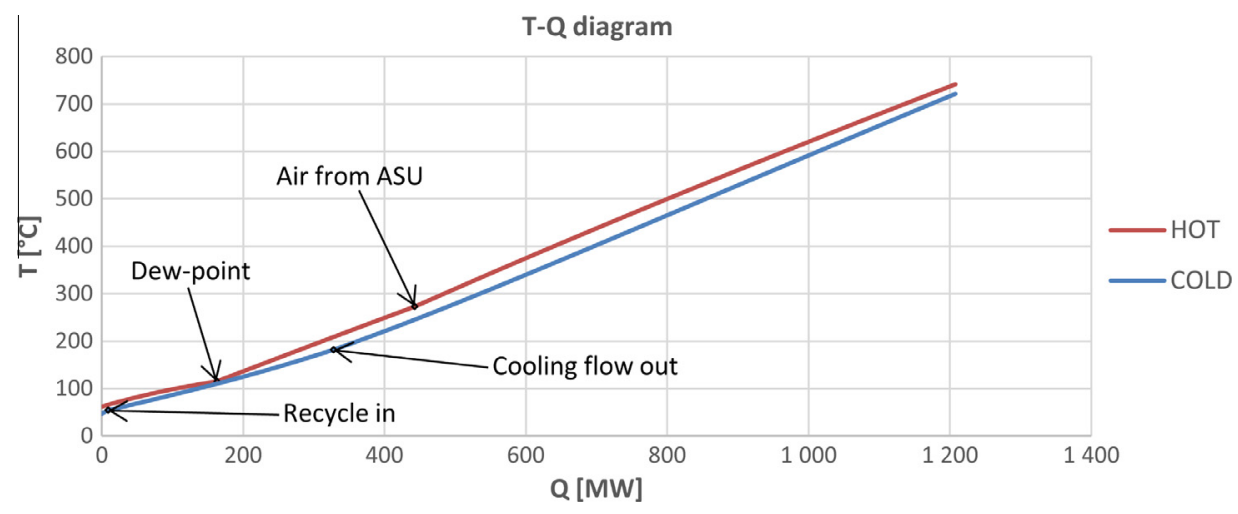

Fig. 4. Possible $T-Q$ diagram of the regenerator. 


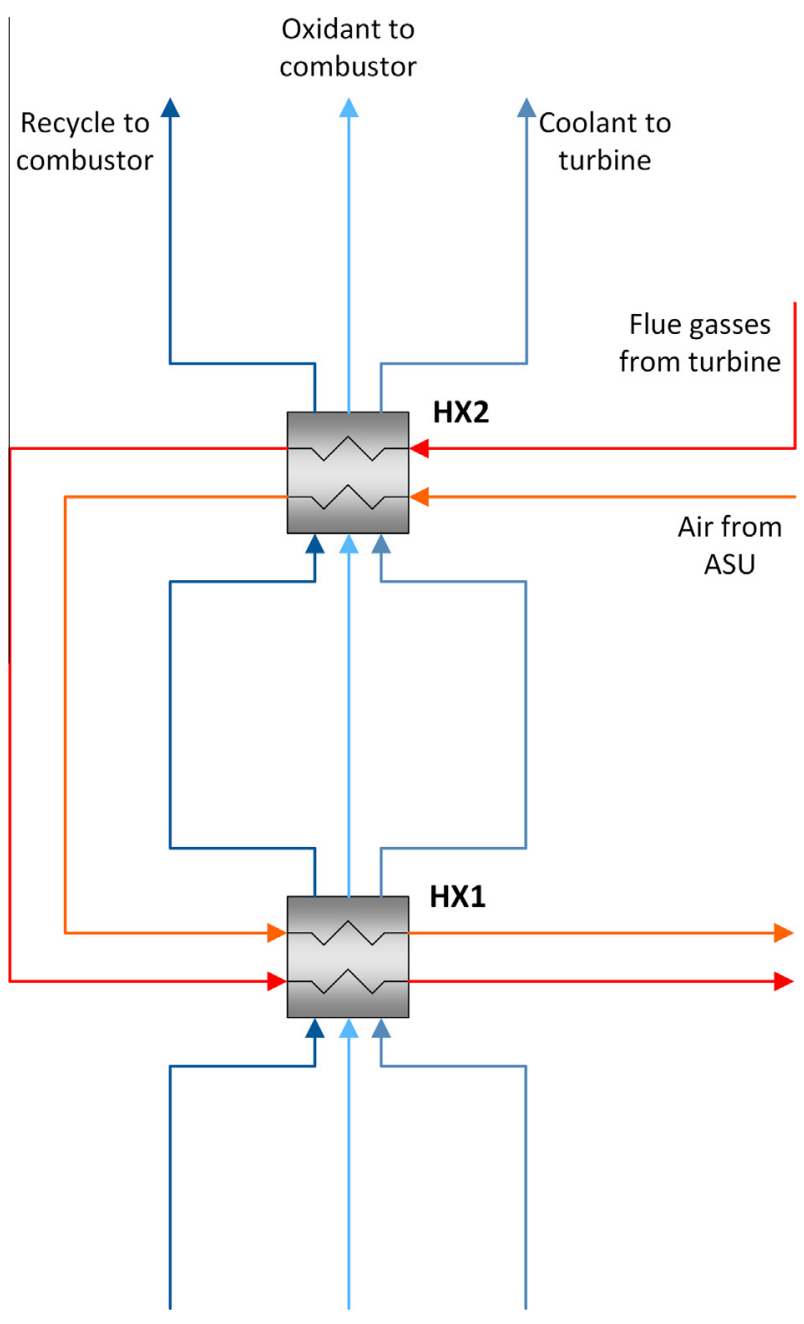

Fig. 5. Flowsheet model of the regenerator.

the hot streams exiting $H X 2$ are set equal to dew point temperature of the flue gases, while the minimum temperature difference at the hot side of $H X 2$ is set equal to $20^{\circ} \mathrm{C}$. The temperatures of the hot flows at the cold end of $H X 1$ and the final temperature of the coolant sent to the turbine are then derived from the energy balances of the two heat exchangers while the temperature of cold flows exiting $H X 1$ is adjusted so as to obtain a minimum temperature difference of $5{ }^{\circ} \mathrm{C}$ in the heat exchanger $H X 1$ (this may occur at the hot side and/or cold side). These design criteria at the basis of the regenerator model allow using the heat available in the flue gases in the most efficient way. Indeed, it maximizes the outlet temperature of the streams sent to the combustor (recycle stream and the oxidant flow) while giving to the turbine cooling flows only the remaining heat. Indeed, while heating up the combustor inlet streams leads to a large advantage in terms of fuel savings (proportional to the heat given to the recycle streams), heating up the turbine cooling flows has the advantage of increasing the turbine power but also the disadvantage of causing an increase of the turbine expansion losses due to the need of a larger flow rate (see the explanation reported in Section 5.1).

\subsection{ASU model}

The ASU has to supply oxygen at 120 bar and $99.5 \%$ purity, as well as medium temperature heat (delivered through the main air compressor after-cooler) for the regenerator. Although the specifications in terms of pressure and purity are quite demanding, they can be met by commercially available designs with three distillation columns [40]. Since building the model of the ASU would lead to inaccurate results due to the lack of performance and operating data of the separation columns required for the model calibration (operating data of the separation columns are not publicly available), it was decided to consider literature data for the ASU power consumption. According to [40], the specific electric consumption of ASUs designed to supply oxygen at 100 bar and $99.5 \%$ purity is about $1365 \mathrm{~kJ} / \mathrm{kg}_{\mathrm{O} 2}$. According to [21], this power consumption becomes $1391 \mathrm{~kJ} / \mathrm{kg}_{\mathrm{O} 2}$ if oxygen (liquid) is pressurized to 120 bar.

\subsection{Equation of State}

In order to perform an accurate evaluation of the thermodynamic performance of the NET Power cycle, it is crucial to adopt a reliable Equation of State model (EoS). The EoS should compute with accuracy the thermo-physical properties which affect the cycle performance: specific volume, enthalpy, entropy, specific heat capacity in the single-phase regions, and phase equilibria (dew and bubble points) in the two-phase region.

To this purpose, it is important to note that the compressed recycle and oxidant streams of the NET Power cycle cannot be modelled as ideal gas mixtures throughout the whole length of the regenerator. Indeed, in the low temperature portion of the component the reduced temperatures of the streams (i.e., the actual temperature divided by the critical temperature) are close to 1 and their reduced pressures (i.e., the actual pressure divided by the critical pressure) are high, indicating that a significant real gas effect occurs. For this reason, particular attention must be paid to the selection of the Equation of State (EoS). To this end, the accuracy of the most suitable equations of states, namely PR (PengRobinson) [41], SRK (Soave-Redlich-Kwong) [42] and BWR-LS (Ben edict-Webb-Rubin-Lee-Starling) [43-45], has been assessed with respect to experimental data available in literature. In the comparison, the default binary interaction parameters of Aspen Plus have been considered, and the experimental data involve binary mixtures of the species relevant to the NET Power cycle: $\mathrm{CO}_{2}-\mathrm{H}_{2} \mathrm{O}, \mathrm{CO}_{2}-$ $\mathrm{O}_{2}$, $\mathrm{CO}-\mathrm{N}_{2}$ and $\mathrm{CO}_{2}-\mathrm{Ar}$. The properties of interest are the specific volume, which describes the volumetric behaviour (crucial to evaluate the specific work in compressors, pumps and expanders) and affects also the thermal behaviour, and the specific heat capacity, which is directly related to the T-Q profile of the stream within a heat exchanger. In addition to this, it is also impor-tant to estimate properly the dew point of $\mathrm{CO}_{2}-\mathrm{H}_{2} \mathrm{O}$ mixtures, since the T$\mathrm{Q}$ profile of the flue gases stream, and hence the effectiveness of the regenerator, is strictly related to the dew point temperature. Unfortunately, for the mixtures of interest, no data are available in literature neither for the estimate of the heat capacity nor for enthalpy, and therefore the focus is only on pvT (pressure-specific volume-temperature) and dew point data, retrieved from [45-48]. Table 2 summarizes the data type, source and range, while the results of the comparison are reported in Table 3.

The assessment shows that PR and SRK provides similar accuracies, reporting average relative percentage errors of $3.4 \%$ and $3.8 \%$, with PR superior for all properties except for the $\mathrm{CO}_{2}-\mathrm{O}_{2}$ density. Instead, BWR-LS predicts well the volumetric behaviour of $\mathrm{CO}_{2}-$ $\mathrm{H}_{2} \mathrm{O}$ and $\mathrm{CO}_{2}$-Ar mixtures but it is less accurate for the other properties, especially for the dew points of $\mathrm{CO}_{2}-\mathrm{H}_{2} \mathrm{O}$ mixtures. Even though there is not a clear superiority of a certain EoS, Peng Robinson appears to be slightly better on average than the others, as also pointed out by Li and Yan [49] (reporting the superiority of Peng Robinson in the calculation of volumetric properties for $\mathrm{CO}_{2}$ mixtures with $\mathrm{N}_{2}, \mathrm{Ar}$ and $\mathrm{O}_{2}$ ). For this reason, Peng Robinson was selected as EoS to model the cycle. Nevertheless the impact of 
Table 2

Experimental data available in literature used to assess the accuracy of the equations of states.

\begin{tabular}{|c|c|c|c|c|c|}
\hline Component 1 & $\mathrm{CO}_{2}$ & $\mathrm{CO}_{2}$ & $\mathrm{CO}_{2}$ & $\mathrm{CO}_{2}$ & $\mathrm{CO}_{2}$ \\
\hline Molar fraction range & $0.633-0.955$ & $0.5651-0.98$ & 0.8709 & 0.9585 & 0.9692 \\
\hline Component 2 & $\mathrm{H}_{2} \mathrm{O}$ & $\mathrm{H}_{2} \mathrm{O}$ & $\mathrm{O}_{2}$ & $\mathrm{~N}_{2}$ & $\mathrm{Ar}$ \\
\hline Molar fraction range & $0.045-0.367$ & $0.02-0.4349$ & 0.1291 & 0.0415 & 0.0308 \\
\hline Temperature range $\left({ }^{\circ} \mathrm{C}\right)$ & $100-232$ & $150-420$ & $30-110$ & $30-110$ & $30-110$ \\
\hline Pressure range (bar) & $3.3-101$ & $80-170$ & $10-200$ & $10-200$ & $10-200$ \\
\hline Number of exp points for the evaluation & 19 & 16 & 100 & 97 & 100 \\
\hline Source & {$[46,47]$} & {$[46,48]$} & [45] & [45] & {$[45]$} \\
\hline Thermodynamic property & DEW point pressure & Density & Density & Density & Density \\
\hline
\end{tabular}

Table 3

Evaluation of EoSs with experimental data. PR = Peng Robinson, SRK = Soave-Redlich-Kwong, BWR-LS = Benedict-Webb-Rubin-Lee-Starling.

\begin{tabular}{|c|c|c|c|c|c|}
\hline Component 1 & Component 2 & Thermodynamic property & $\%$ error $\mathrm{PR}=(\mathrm{PR}-\mathrm{REF}) / \mathrm{REF} \%$ & $\%$ error SRK = (SRK-REF)/REF\% & $\%$ error BWR-LS $=($ BWR-LS-REF $) /$ REF\% \\
\hline $\mathrm{CO}_{2}$ & $\mathrm{H}_{2} \mathrm{O}$ & DEW point pressure & $5.7 \%$ & $7.5 \%$ & $14.7 \%$ \\
\hline $\mathrm{CO}_{2}$ & $\mathrm{H}_{2} \mathrm{O}$ & Density & $1.6 \%$ & $2.4 \%$ & $1.5 \%$ \\
\hline $\mathrm{CO}_{2}$ & $\mathrm{O}_{2}$ & Density & $5.2 \%$ & $2.2 \%$ & $4.4 \%$ \\
\hline $\mathrm{CO}_{2}$ & $\mathrm{~N}_{2}$ & Density & $2.6 \%$ & $2.7 \%$ & $3.0 \%$ \\
\hline \multirow[t]{3}{*}{$\mathrm{CO}_{2}$} & $\mathrm{Ar}$ & Density & $2.0 \%$ & $4.0 \%$ & $1.3 \%$ \\
\hline & & & Average \% error PR & Average \% error SRK & Average \% error BWR-LS \\
\hline & & & $3.4 \%$ & $3.8 \%$ & $5.0 \%$ \\
\hline
\end{tabular}

the equation of state on the cycle performance is analysed in Section 5.8 .

\subsection{Basis of design and assumptions}

In order to make a fair comparison between the optimized plant of this work and the plant originally designed by IEA in [21], this study considers the same ambient, fuel (natural gas) and boundary conditions of [21]. The natural gas composition and main properties are reported in Table 4.

It is assumed that cooling water at $15{ }^{\circ} \mathrm{C}$ is available at the plant site and it allows cooling the cycle streams to $26^{\circ} \mathrm{C}$. Note that the cooling water temperature has a considerable effect on the overall performance of the cycle, as discussed in Section. The starting pressure of the dense phase compression is related to the cooling water temperature, as indicated in [21]: the pressure is adjusted so as to have a density around $700 \mathrm{~kg} / \mathrm{m}^{3}$ at the inlet of the dense-phase compressor. For the minimum cycle temperature of $26^{\circ} \mathrm{C}$, this pressure is equal to approximately 80 bar. The efficiency values assumed for the turbomachines are reported in Table 5 .

In the regenerator, the pinch-point temperature difference is set to $5{ }^{\circ} \mathrm{C}$, while the temperature difference at the hot end side has to be equal or greater than $20^{\circ} \mathrm{C}$. The heat available in the exhaust flow and in the compressed air is used firstly to increase the temperature of the recycle stream and the oxidant flow, while the tem-

Table 4

Natural gas composition and most relevant thermodynamic properties.

\begin{tabular}{ll}
\hline Natural gas analysis, vol\% & \\
\hline Methane & 89 \\
Ethane & 7 \\
Propane & 1 \\
Butane & 0.1 \\
Pentane & 0.01 \\
$\mathrm{CO}_{2}$ & 2 \\
$\mathrm{~N}_{2}$ & 0.89 \\
Total & 100 \\
LHV $(\mathrm{MJ} / \mathrm{kg})$ & 46.502 \\
Temperature $\left({ }^{\circ} \mathrm{C}\right)$ & 15 \\
Pressure $($ bar $)$ & 70 \\
\hline
\end{tabular}

Table 5

Main performance assumptions of this study.

\begin{tabular}{|c|c|c|c|c|}
\hline \multicolumn{4}{|c|}{ Turbomachine efficiency } & Value \\
\hline \multicolumn{4}{|c|}{ Isentropic efficiency of vapour phase compressor $\eta_{\text {ise }}$} & 0.9 \\
\hline \multicolumn{4}{|c|}{ Hydraulic efficiency of dense phase pump $\eta_{\text {hyd }}$} & 0.85 \\
\hline \multicolumn{4}{|c|}{ Polytropic efficiency of natural gas compressor $\eta_{p o l}$} & 0.85 \\
\hline \multicolumn{4}{|c|}{ Polytropic efficiency of main ASU compressor $\eta_{p o l}$} & 0.85 \\
\hline \multirow{2}{*}{\multicolumn{4}{|c|}{ Isentropic efficiency of turbine stages (see model) $\eta_{\text {ise }}$}} & 0.89 \\
\hline Mechanical efficiency of all turbomachines $\eta_{\text {mec }}$ & & & & 0.98 \\
\hline Pressure drops & $\begin{array}{l}\text { Inlet } \\
\text { press. } \\
\text { (bar) }\end{array}$ & $\begin{array}{l}\text { Press. drop for } \\
\text { base case (bar) }\end{array}$ & $\begin{array}{l}\text { Press } \\
\text { sensi }\end{array}$ & pt. (\%) \\
\hline $\begin{array}{c}\text { Regen. high } \\
\text { pressure } \\
\text { flows }\end{array}$ & 305 & 1.6 & 0.52 & \\
\hline $\begin{array}{c}\text { Regen. low } \\
\text { pressure } \\
\text { flows }\end{array}$ & 34 & 0.8 & 2.35 & \\
\hline Combustor & 303 & 3 & 0.99 & \\
\hline $\begin{array}{r}\text { Condenser and } \\
\text { Intercoolers }\end{array}$ & $20-120$ & $0.4-2.4$ & 2.0 & \\
\hline
\end{tabular}

perature of the turbine blades cooling flow is variable depending on the heat still available in the hot streams.

In all the cases analysed in this work, the recycled $\mathrm{CO}_{2}$ mixed with the oxygen flow is set so as to obtain an oxidant stream (stream OX-1 in Fig. 1) with an oxygen molar fraction equal to $13.34 \%$, as in [21]. The oxygen flow rate is selected in order to carry out the combustion with an oxygen excess of $3 \%$ compared to the stoichiometric value, including the oxygen contained in the recycle flow used to limit the firing temperature, as in [21,50,51]. Heat exchanger, intercoolers, condenser and combustor pressure drops were estimated according to the values reported in [21] and are reported in Table 5. Then, in order to take into account pressure variations during the sensitivity analysis and optimization, pressure drops where expressed as a percentage of the inlet value of each component, according to the ranges reported in Table 5. Compared to the IEA report [21], more conservative values have been assumed for the hydraulic efficiencies of pumps (see Table 5) and the regenerator pinch point temperature difference $\left(5^{\circ} \mathrm{C}\right.$ vs. $\left.4.5^{\circ} \mathrm{C}\right)$. 


\section{Evaluation of the Base Case cycle}

As starting point for this analysis, the Net Power cycle designed in [21] is considered and reproduced. It adopts the same stream conditions (pressure, temperature, etc.) and values of the key cycle variables, as reported in Table 6 . In any case, it is worth noting that some data (e.g., hydraulic efficiency of pumps, components pressure drop, etc.) are not reported in [21] and, for this reason, they have been assumed on the basis of sound engineering criteria. This is the reason why the results of this work slightly differ from those reported in [21].

The results of the simulation are shown in Table 7 where they are also compared with those of [21] (assuming half plant size). The same fuel input is considered for the two designs in order to ease the comparison. The discrepancies between the performance of the two cycles are due to the differences in the assumptions mentioned before.

Fig. 6 and Table 8 highlights the comparison between the results of the two works.

As shown in Table 7, the power consumption of the compression section is 7.2 $\mathrm{MW}_{\mathrm{e}}$ greater than the one in [21], even though the total recycle flow rate is lower, and the recycle gas to regenerator temperature is $4.2^{\circ} \mathrm{C}$ higher. This may be due to the different efficiencies assumed for pumps.

The difference in the turbine power output between this study and [21] is mainly due to the turbine cooling flow. Indeed, in the analysis by IEA, the cooling flow is heated up to $284^{\circ} \mathrm{C}$ within the regenerator (assuming a pinch-point temperature difference of $4.5^{\circ}$ C), while in this study it is heated up to only $182^{\circ} \mathrm{C}$, as a

Table 6

Key cycle variables of the Base Case.

\begin{tabular}{llr}
\hline Parameter & Unit & Value \\
\hline Combustor outlet temperature & ${ }^{\circ} \mathrm{C}$ & 1150 \\
Turbine inlet pressure & bar & 300 \\
Turbine outlet pressure & bar & 34 \\
Regenerator hot side $\Delta T$ & ${ }^{\circ} \mathrm{C}$ & 20 \\
Regenerator pinch-point $\Delta T$ & ${ }^{\circ} \mathrm{C}$ & 5 \\
Minimum fluid temperature & ${ }^{\circ} \mathrm{C}$ & 26 \\
\hline
\end{tabular}

Table 7

Performance evaluation of the Base Case cycle.

\begin{tabular}{|c|c|c|c|}
\hline & Unit & $\begin{array}{l}\text { Results of this } \\
\text { work }\end{array}$ & $\begin{array}{l}\text { Results of } \\
{[21]}\end{array}$ \\
\hline $\begin{array}{l}\text { Thermal energy of feedstock } \\
\text { (LHV) }\end{array}$ & $\mathrm{MW}_{\text {th }}$ & 768.31 & 768.31 \\
\hline Turbine power output & $\mathrm{MW}_{\mathrm{e}}$ & 622.42 & 631.95 \\
\hline $\begin{array}{l}\text { Recycle flow compressors } \\
\text { consumption }\end{array}$ & $\mathrm{MW}_{\mathrm{e}}$ & 111.15 & 103.95 \\
\hline NG compressor & $\mathrm{MW}_{\mathrm{e}}$ & 4.18 & 4.75 \\
\hline Air separation unit & $\mathrm{MW}_{\mathrm{e}}$ & 85.54 & 85.45 \\
\hline Net electric power output & $\mathrm{MW}_{\mathrm{e}}$ & 419.31 & 422.95 \\
\hline Net specific work ${ }^{a}$ & $\mathrm{~kJ} / \mathrm{kg}$ & 329.91 & 334.43 \\
\hline Net electric efficiency (LHV) & $\%$ & 54.58 & 55.05 \\
\hline Turbine outlet temperature & ${ }^{\circ} \mathrm{C}$ & 741.2 & 740 \\
\hline Recycle flow final temperature & ${ }^{\circ} \mathrm{C}$ & 721.2 & 720 \\
\hline Cooling flow final temperature & ${ }^{\circ} \mathrm{C}$ & 183 & 284 \\
\hline $\begin{array}{l}\text { Flue gas to condenser } \\
\text { temperature }\end{array}$ & ${ }^{\circ} \mathrm{C}$ & 62.1 & 55 \\
\hline $\begin{array}{l}\text { Recycle flow to regenerator } \\
\text { temperature }\end{array}$ & ${ }^{\circ} \mathrm{C}$ & 54.2 & 50 \\
\hline Turbine inlet flow rate & $\mathrm{kg} / \mathrm{s}$ & 1271.0 & 1264.7 \\
\hline Cooling flow rate & $\mathrm{kg} / \mathrm{s}$ & 99.4 & 145 \\
\hline $\begin{array}{l}\text { Total recycle flow rate (with } \\
\text { oxygen) }\end{array}$ & $\mathrm{kg} / \mathrm{s}$ & 1353.9 & 1393.1 \\
\hline
\end{tabular}

${ }^{\text {a }}$ Net electric power output/turbine inlet mass flow rate. result of the slightly higher pinch-point temperature difference assumed here (equal to $5^{\circ} \mathrm{C}$ ). Due to the hotter cooling flow, the turbine of the cycle considered in [21] requires a larger cooling flow rate to keep the blades at the same metal temperature $\left(860{ }^{\circ} \mathrm{C}\right)$. Therefore, the higher pinch-point temperature difference of the regenerator and the lower pumps efficiency lead to an over-all reduction of the net electric efficiency of 0.47 percentage point compared to [21].

\section{Sensitivity analyses}

The aim of this section is to analyse the influence of the key parameters and modelling assumptions on the cycle performance. First the following cycle parameters are varied in order to understand their effects on the efficiency of the cycle:

- Turbine inlet temperature (Section 5.1).

- Cooling flow temperature (Sections 5.2).

- Inlet and outlet pressures of the turbine (Sections 5.3 and 5.4).

Then, the sensitivity analysis is performed with respect to the main modelling and technological assumptions, namely:

- Cooling water temperature (Section 5.5).

- Turbine and compressor efficiency (Section 5.6).

- Power consumption of the air separation unit (Section 5.7).

- Equation of states (Section 5.8).

\subsection{Sensitivity to combustor outlet temperature}

In this Section the model of the cycle is used to evaluate the effect of the combustor outlet temperature by varying this temperature from $1050{ }^{\circ} \mathrm{C}$ to $1250{ }^{\circ} \mathrm{C}$ and repeating the cycle simulation. All the other design parameters and assumptions (e.g., the turbine inlet and outlet pressures) are kept constant (same values as described before). Detailed results are reported in Table A- 1 of the supplementary online material while a summary of the most important findings is shown in Figs. 7 and 8. Fig. 7 shows the global effect of the combustor outlet temperature on the net electric efficiency and net specific work of the cycle while Fig. 8 reports the plot of the mass flow rates of the key cycle streams. Similarly to gas turbine cycles, the net specific work of the cycle is defined as the ratio between the net power output and the turbine inlet mass flow rate.

As shown in Fig. 7, the net specific work of the cycle increases with increasing COT, as it happens for both gas cycles and Rankine cycles because of the increase of the turbine expansion work. Instead, the cycle efficiency has an unusual trend: the maximum of the cycle efficiency occurs at a combustor outlet temperature of about $1150{ }^{\circ} \mathrm{C}$, a rather low value compared to that of standard gas turbines. This result agrees with that found in [21], reporting that the maximum efficiency is between $1150{ }^{\circ} \mathrm{C}$ and $1200^{\circ} \mathrm{C}$.

The unexpected efficiency decrease at high combustor outlet temperatures is mainly due to the following two causes:

1. The considerable increase of the turbine cooling flow rates.

2. The increase of the heat transfer irreversibility in the regenerator.

For a given fuel mass flow rate, in order to increase the combustor outlet temperature (COT), the mass flow rate of the recycled flue gases used to moderate the combustion temperature (RE-4 in Fig. 6) must be decreased, as shown in Fig. 8. As a consequence of the higher turbine outlet temperature (TOT) and lower recycle flow rate, more heat is available in the regenerator and the temper- 


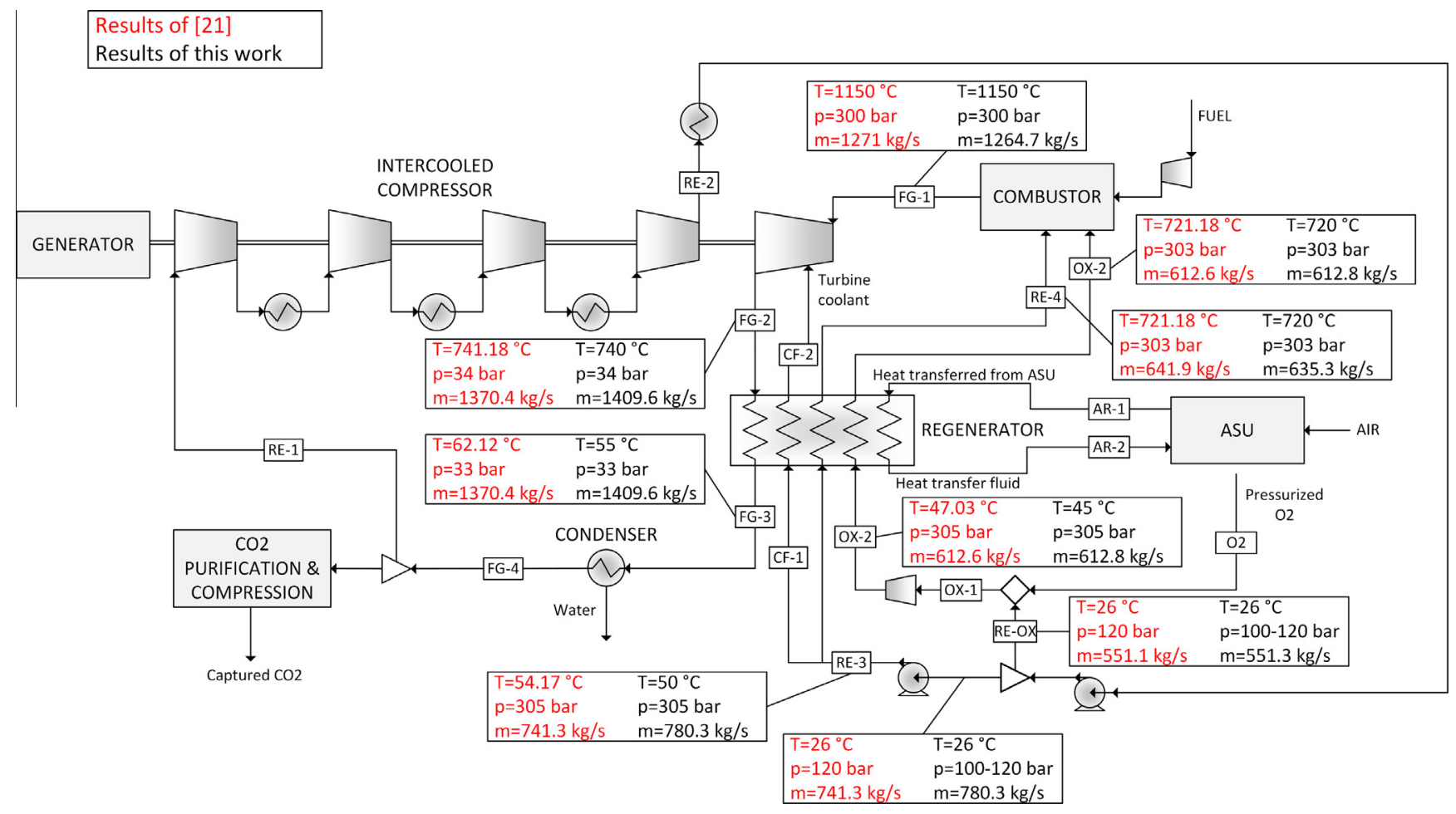

Fig. 6. Comparison between the results of this study and those reported in the IEA report [21].

Table 8

Comparison between the results of this study and those reported in the IEA report [21].

\begin{tabular}{|c|c|c|c|c|c|c|c|c|c|c|}
\hline & Vol\% & $\mathrm{Ar}$ & $\mathrm{CO}_{2}$ & $\mathrm{H}_{2} \mathrm{O}$ & $\mathrm{N}_{2}$ & $\mathrm{O}_{2}$ & Total & Temp. $\left[{ }^{\circ} \mathrm{C}\right]$ & Press. [bar] & M. flow rate $[\mathrm{kg} / \mathrm{s}]$ \\
\hline \multirow{2}{*}{ RE-3 } & This work & 0.57 & 97.92 & 0.13 & 1.18 & 0.20 & 100 & 54.2 & 305 & 741.3 \\
\hline & {$[21]$} & 0.57 & 97.88 & 0.15 & 1.18 & 0.21 & 100 & 50.0 & 305 & 780.3 \\
\hline \multirow[t]{2}{*}{$\mathrm{RE}-4$} & This work & 0.57 & 97.92 & 0.13 & 1.18 & 0.20 & 100 & 721.2 & 303 & 641.9 \\
\hline & [21] & 0.57 & 97.88 & 0.15 & 1.18 & 0.21 & 100 & 720.0 & 303 & 635.3 \\
\hline \multirow[t]{2}{*}{ OX-1 } & This work & 0.53 & 84.96 & 0.11 & 1.05 & 13.34 & 100 & 47.0 & 305 & 612.6 \\
\hline & {$[21]$} & 0.53 & 84.94 & 0.13 & 1.05 & 13.34 & 100 & 45.0 & 305 & 612.8 \\
\hline \multirow[t]{2}{*}{ OX-2 } & This work & 0.53 & 84.96 & 0.11 & 1.05 & 13.34 & 100 & 721.2 & 303 & 612.6 \\
\hline & {$[21]$} & 0.53 & 84.94 & 0.13 & 1.05 & 13.34 & 100 & 720.0 & 303 & 612.8 \\
\hline \multirow[t]{2}{*}{ FG-1 } & This work & 0.53 & 91.86 & 6.31 & 1.11 & 0.19 & 100 & 1150.0 & 300 & 1271.0 \\
\hline & {$[21]$} & 0.53 & 91.80 & 6.36 & 1.11 & 0.20 & 100 & 1150.0 & 300 & 1264.7 \\
\hline \multirow[t]{2}{*}{ FG-2 } & This work & 0.54 & 92.29 & 5.87 & 1.11 & 0.19 & 100 & 741.2 & 34 & 1370.4 \\
\hline & {$[21]$} & 0.54 & 92.41 & 5.74 & 1.12 & 0.20 & 100 & 740.0 & 34 & 1409.6 \\
\hline \multirow[t]{2}{*}{ FG-3 } & This work & 0.54 & 92.29 & 5.87 & 1.11 & 0.19 & 100 & 62.1 & 33 & 1370.4 \\
\hline & {$[21]$} & 0.54 & 92.41 & 5.74 & 1.12 & 0.20 & 100 & 55.0 & 33 & 1409.6 \\
\hline
\end{tabular}

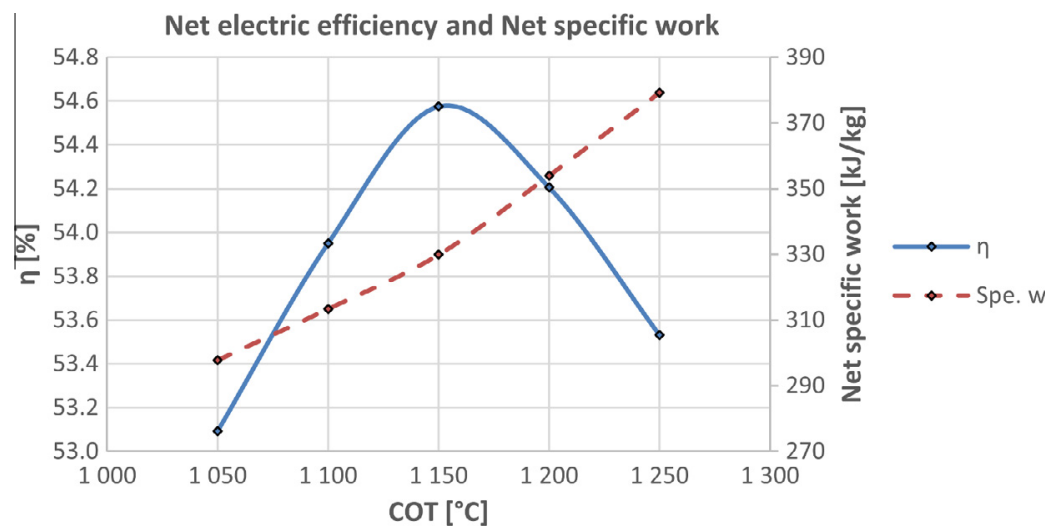

Fig. 7. Net electric efficiency and Net specific work of the NET Power cycle as a function of the combustor outlet temperature (sensitivity analysis). 


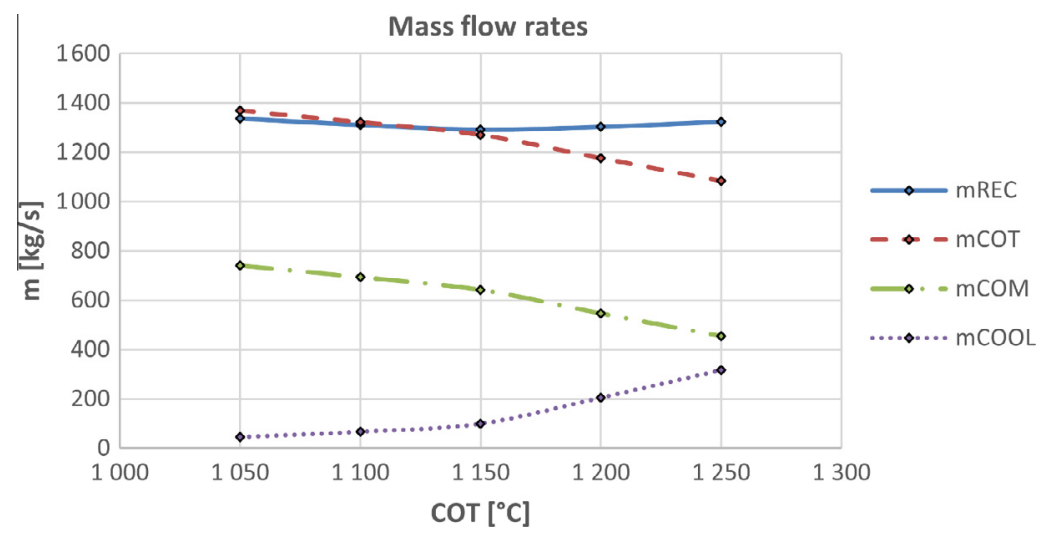

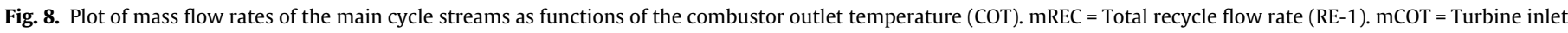
flow rate $(\mathrm{FG}-1)$. $\mathrm{mCOM}=$ Combustor moderating temperature flow rate $(\mathrm{RE}-4)$. $\mathrm{mCOOL}=$ Turbine coolant flow rate $(\mathrm{CF}-2)$.

atures of the recycle gas and turbine cooling flows increase. While the increase of recycle temperature is beneficial to the cycle efficiency, the increase of the turbine cooling flow temperature is deleterious. Indeed, in order to maintain the turbine blades at the same metal temperature, the cooling stream mass flow rate must be increased, leading to: (i) higher fluid-dynamic losses in the turbine expansion; (ii) lower cycle efficiency; (iii) higher compression power consumption.

As far as point (i) is concerned, it is worth recalling that the injection of cooling streams causes an irreversible reduction of pressure and flow velocity [35] with an associated penalty of expansion efficiency as a result of their lower velocity compared to the main stream. As far as point (ii) is concerned, it is important to note that the stream of cooling flows reaches a temperature considerably lower (a few hundred degrees Celsius above their injection temperature [36]) than the maximum temperature of the cycle (which is essentially the turbine inlet temperature). As a consequence, the turbine cooling flows evolve within a thermodynamic cycle with a rather limited efficiency which negatively affects the overall cycle efficiency. The weight of such penalty is proportional to the ratio between the flow rate of the cooling streams and the total flow rate. For the three motivations listed above (i-iii), the large increase of cooling flow rate appears to be the main responsible of the unusual efficiency trend of the NET Power cycle as a function of the maximum cycle temperature (COT), with an optimum at significant lower temperature compared to a standard gas turbines [35,52]. On the other hand, one could argue that this increase of cooling flow rate could be avoided if the cooling flow temperature is kept constant and not raised to recover the available heat of the exhaust gases. In order to answer this question, a sensitivity analysis with respect to the cooling flow temperature has been carried out in Section 5.2.

The second effect causing an efficiency penalty at high values of COT is the increase of the heat transfer temperature difference within the regenerator, as shown in Fig. 9. The large heat transfer temperature difference denotes a destruction of exergy within the heat recovery process from the hot flue gases. However, this second effect has a minor impact compared to the increase of the turbine cooling flow rates.

In order to prove that the reduction of net electric efficiency at high COT is mainly due to the need of large turbine cooling flows, we repeated the sensitivity analysis on combustor outlet temperature by considering an uncooled turbine (an ideal turbine which can withstand the high gas temperatures without the aid of a cooling system). All the cycle design parameters are maintained equal to those of the previous analysis. The simulation results are reported in Table A- 2 of the supplementary online material, while the efficiency is plotted in Fig. 10.

It has to be noticed that when the turbine COT is higher than $1750{ }^{\circ} \mathrm{C}$ the hot end temperature difference of the regenerator reaches the minimum value of $20^{\circ} \mathrm{C}$. Above this temperature, the slope of the plot suddenly decreases because the increase of COT gives only a marginal benefit to the net electric efficiency. This is a result of the worst heat integration in the regenerator, which causes the pinch point to move to the hot end, with an increase of thermal power dissipated within the condenser. At high

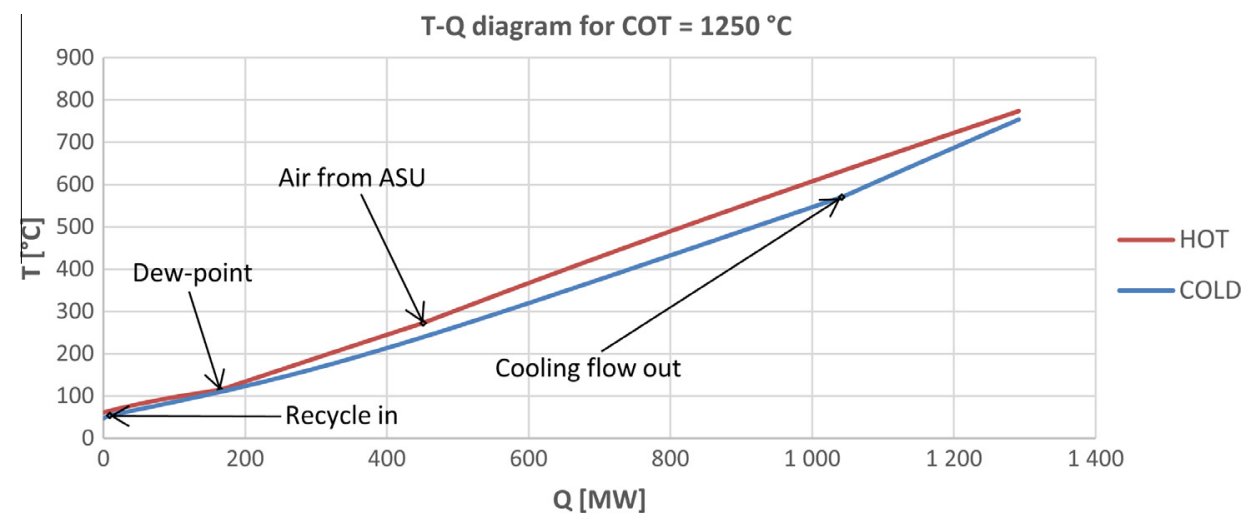

Fig. 9. $T-Q$ (temperature-enthalpy) diagram of the regenerator for the case with combustor outlet temperature $=1250{ }^{\circ} \mathrm{C}$. 


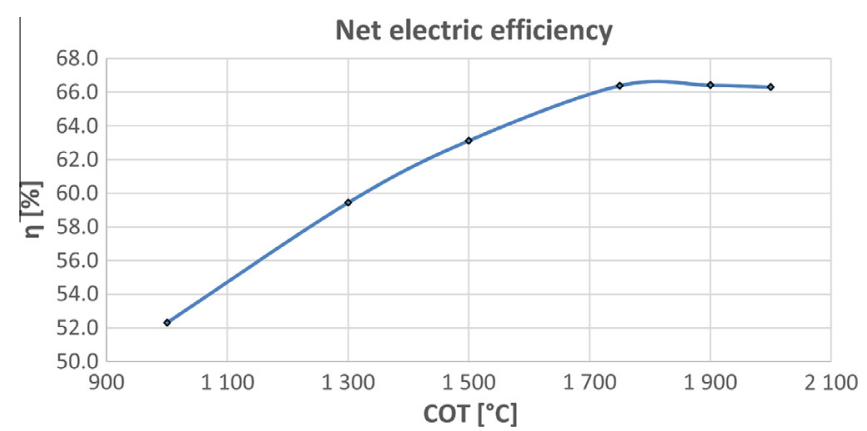

Fig. 10. Net electric efficiency of the cycle with an uncooled turbine as a function of the combustor outlet temperature.

combustor outlet temperatures, the heat capacity of the recycle stream decreases due to its smaller mass flow rate and it is not sufficient to recover all the heat of the exhaust gases.

It is worth noticing that the net electric efficiency value obtained with an uncooled turbine and a combustor outlet temperature of $1300{ }^{\circ} \mathrm{C}$ is close to the efficiency value claimed by the developers in [15].

\subsection{Sensitivity to turbine cooling flow temperature}

In this Section, the performances of the cycle are evaluated by progressively reducing the temperature of turbine cooling flows (CF-2). This variation causes a reduction of thermal power required by the cold streams within the regenerator, which causes an increase of the pinch-point temperature difference and of the heat wasted (rejected to the environment), as shown in Table A-3 of the supplementary online material and Fig. 11. The plot of the net electric efficiency as a function of the cooling flow temperature is reported in Fig. 12.

Results show that, although increasing the cooling flow temperature raises the amount of coolant flow required as well as the turbine expansion losses, recovering the surplus heat of the regenerator is more advantageous than wasting it. Indeed, if the turbine cooling flow is not preheated, the surplus heat of the regenerator (made available from the exhaust gases) is wasted thereby causing a large exergy loss.

\subsection{Sensitivity to turbine inlet pressure}

This section describes the impact of turbine inlet pressure variation on NET Power cycle efficiency. Six different pressures are

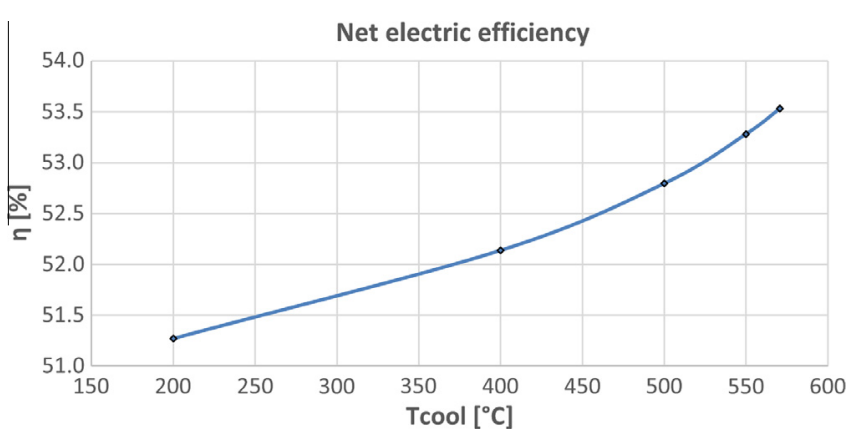

Fig. 12. Plot of the net electric efficiency as a function of the cooling flow temperature (sensitivity analysis).

considered: 240 bar, 260 bar, 280 bar, 300 bar, 320 bar and 360 bar. In all cases, the outlet pressure and the combustor outlet temperature are kept constant at 34 bar and $1150{ }^{\circ} \mathrm{C}$. Table A-4 of the supplementary online material and Fig. 13 report the most significant results and performance indexes.

The most interesting results of this analysis are (i) the existence of an optimal range for the turbine inlet pressure, estimated to be between 260 and 300 bar; (ii) the small variation of the cycle efficiency in the range $260-320$ bar. In the range $260-300$ bar, the decrease of the net specific work due to the reduction of the turbine inlet pressure (see Fig. 13) is compensated by the improvement of the heat recovery occurring in the regenerator: thanks to the increase of the turbine outlet temperature, the recycle streams are preheated to a higher temperature with an associated positive effect on the cycle efficiency (i.e., less input heat necessary to take the streams to the combustor outlet temperature). This finding is important as it notices the possibility of reducing the turbine inlet pressure to 260 bar (thus the mechanical stress of the cycle components) without major efficiency penalty.

At pressures lower than 260 bar, the specific heat capacity of the pressurized recycle streams increases in the low temperature range (as shown in Table 9 for temperatures below $350 \mathrm{~K}$ ) and this causes a deficit of heat in the low temperature section of the regen-erator. This deficit is satisfied by the available high temperature heat of the flue gases with a corresponding penalty in the heat integration of the regenerator (see Fig. 14). Using high temperature heat to heat up cold streams leads to an exergy penalty which jus-tifies the marked efficiency drop below 260 bar. On the other hand, above 300 bar, the turbine outlet temperature becomes insufficient to preheat the recycle streams to high temperature. Moreover, high pressures above 300 bar causes the reduction of the specific heat

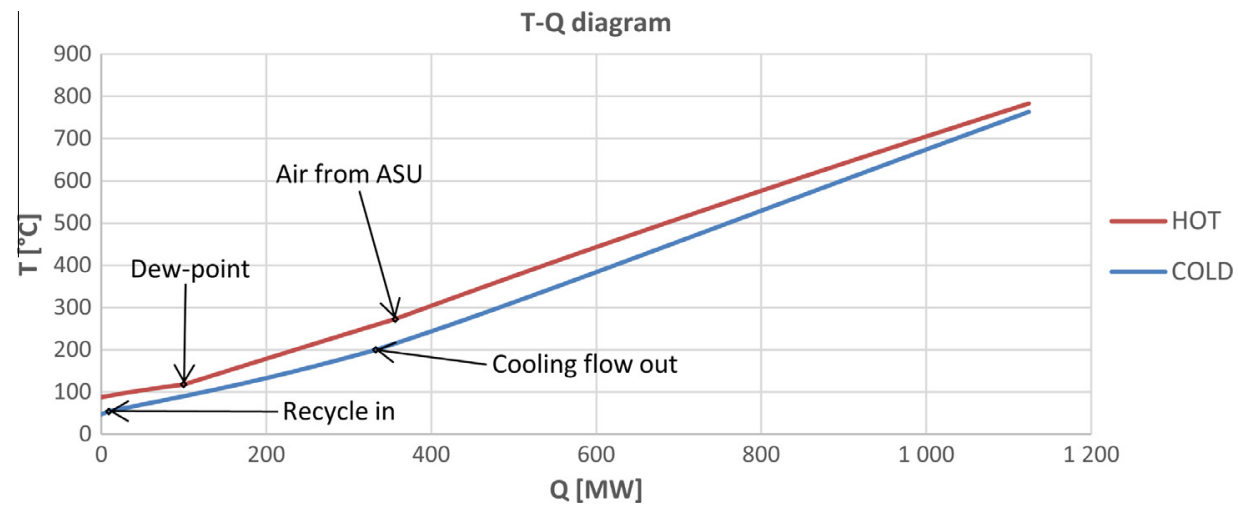

Fig. 11. $T$ - $Q$ diagram of the regenerator for the case with cooling flow temperature $T_{\mathrm{CF}-2}=200{ }^{\circ} \mathrm{C}$ (sensitivity to turbine blades cooling flow temperature). 


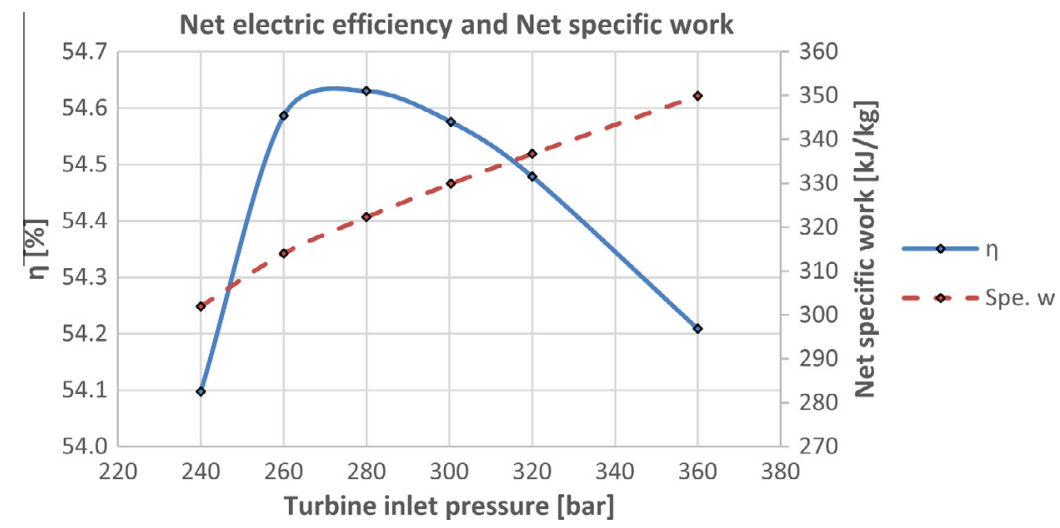

Fig. 13. Plot of the net electric efficiency and net specific work as a function of the turbine inlet pressure (sensitivity analysis).

Table 9

Specific heat capacity at constant pressure of pure $\mathrm{CO}_{2}$ at different pressures.

\begin{tabular}{|c|c|c|c|}
\hline Temperature (K) & 100 bar & 200 bar & 300 bar \\
\hline & \multicolumn{3}{|c|}{$\mathrm{CO}_{2}$ constant pressure heat capacity $(\mathrm{kJ} / \mathrm{kg} \mathrm{K})$} \\
\hline 350 & 1.96 & 2.57 & 2.00 \\
\hline 400 & 1.32 & 1.86 & 1.90 \\
\hline 450 & 1.20 & 1.47 & 1.63 \\
\hline 500 & 1.17 & 1.34 & 1.47 \\
\hline 600 & 1.16 & 1.24 & 1.31 \\
\hline 750 & 1.18 & 1.21 & 1.23 \\
\hline 1000 & 1.25 & 1.27 & 1.28 \\
\hline
\end{tabular}

capacity of the pressurized recycle stream at low temperatures (see Table 9), hence reducing the recovery of low temperature heat in the regenerator (this phenomenon is confirmed by the increase of the temperature of flue gas entering the condenser, as indicated in Table A-4 of the supplementary online material).

\subsection{Sensitivity to turbine outlet pressure}

Another key parameter of the cycle is the turbine outlet pressure. Six cases have been considered: 28 bar, 32 bar, 34 bar, 36 bar, 40 bar and 44 bar. Performance figures and the most significant thermodynamic conditions are reported in Table A-5 of the supplementary online material.

An increase of the outlet pressure decreases the power generated by the turbine and causes a reduction of the power required by the vapour phase $\mathrm{CO}_{2}$ recycle compressor. The latter effect is

(a) T-Q diagram for TIP = 240 bar

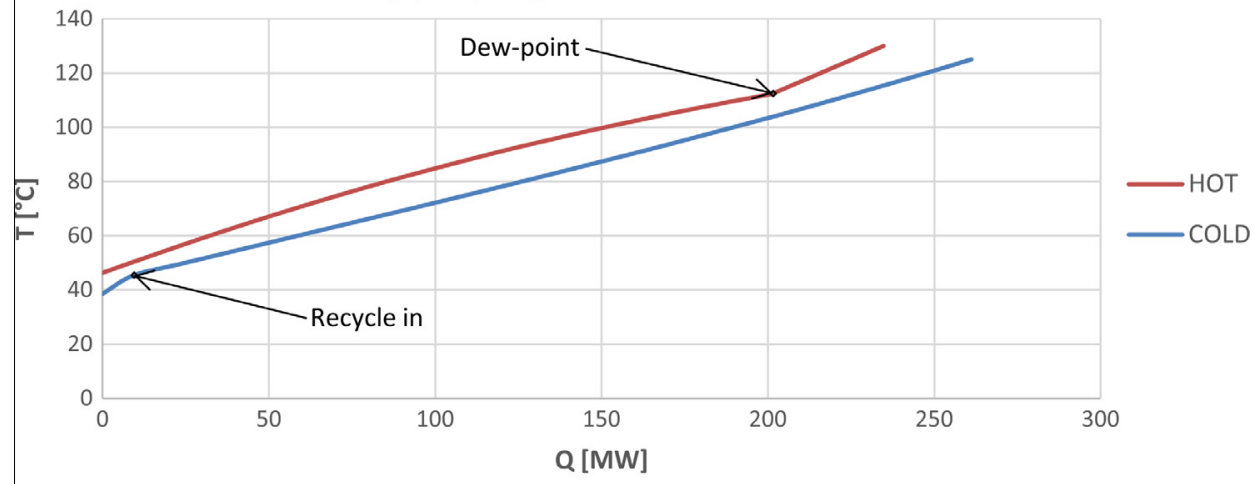

(b) T-Q diagram for TIP $=\mathbf{2 8 0}$ bar

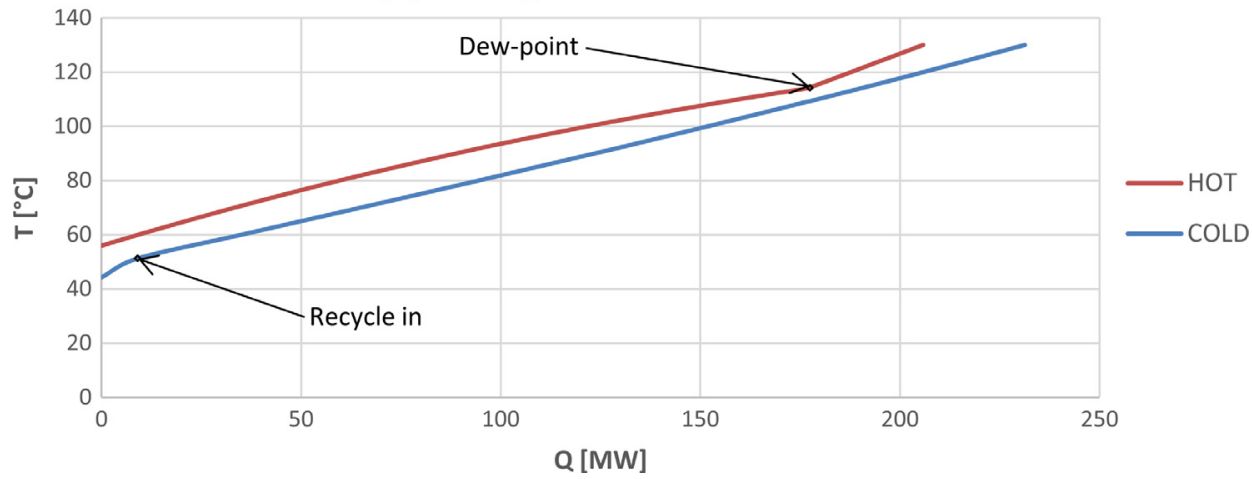

Fig. 14. (a) $T$ - $Q$ diagram of the LT section of the regenerator for turbine inlet pressure (TIP) $=240$ bar, (b) $T$ - $Q$ diagram of the LT section of the regenerator for turbine inlet pressure $(\mathrm{TIP})=280 \mathrm{bar}$ 


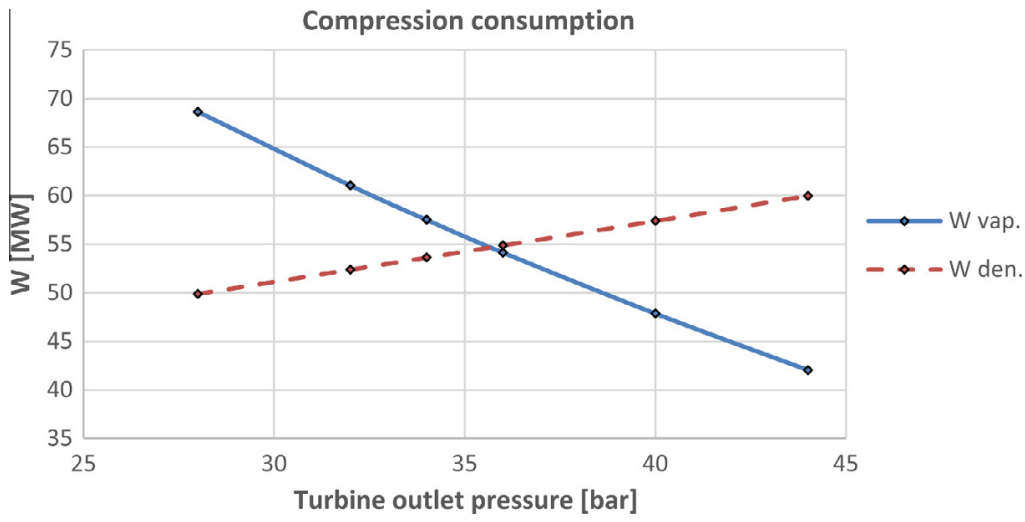

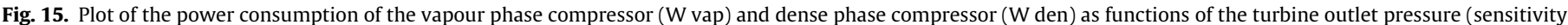
analysis).

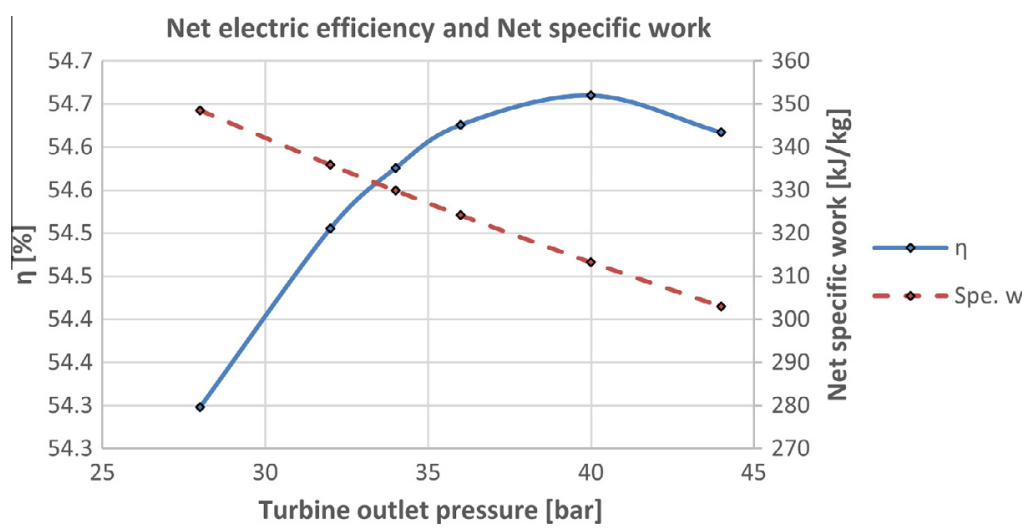

Fig. 16. Plot of the net electric efficiency and net specific work as a function of the turbine outlet pressure (sensitivity analysis).

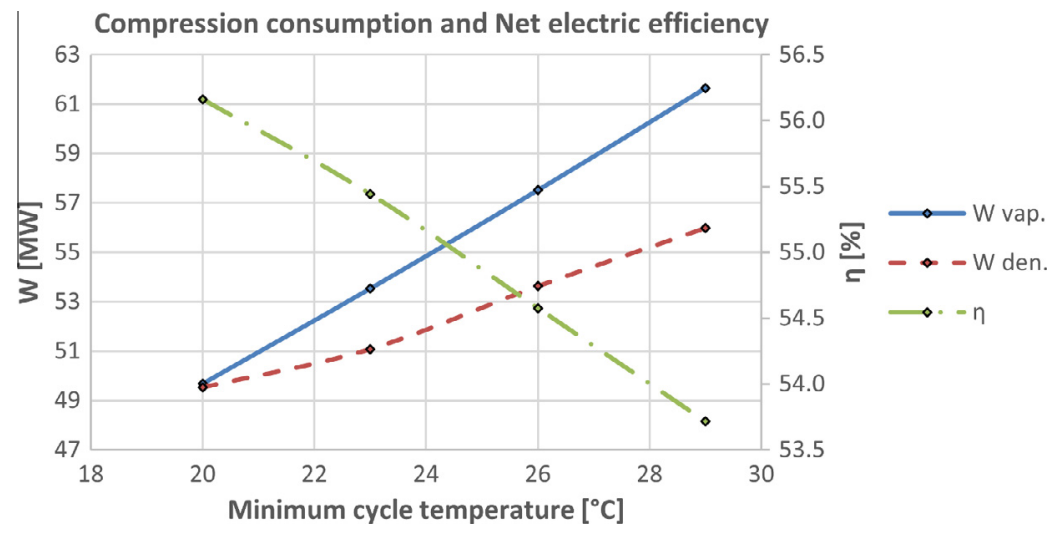

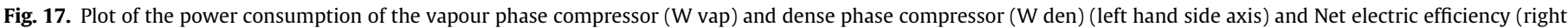
hand side axis) as functions of the minimum cycle temperature (related to the cooling water temperature) (sensitivity analysis).

a consequence of the reduction of the pressure variation required to reach the dense phase region, as shown in Fig. 15.

Fig. 16 shows the influence of the turbine outlet pressure on the net electric efficiency of the plant. There is an optimum at 40 bar, and the curve is quite flat around the maximum (in the range 3543 bar).

\subsection{Sensitivity to cooling water temperature}

The influence of the cooling water temperature is analysed by varying the minimum temperature of the cycle, i.e., the tempera- ture at the exit of the intercoolers and condenser, from $20^{\circ} \mathrm{C}$ to $29^{\circ} \mathrm{C}$. The cooling water temperature directly influences the pressure at which the dense phase compression of $\mathrm{CO}_{2}$ begins (RE-2), due to the relation existing between bubble-point temperature and pressure of the $\mathrm{CO}_{2}-\mathrm{H}_{2} \mathrm{O}$ mixture. In order to avoid cavitation at the suction side of the dense phase pump, the inlet pressure is chosen such that the density of the inlet stream (RE-2) is comparable or greater than that of the Base Case (namely $639.1 \mathrm{~kg} / \mathrm{m}^{3}$ ). Table A-6 of the supplementary online material reports pressure values of the dense phase inlet section determined according to this approach. 


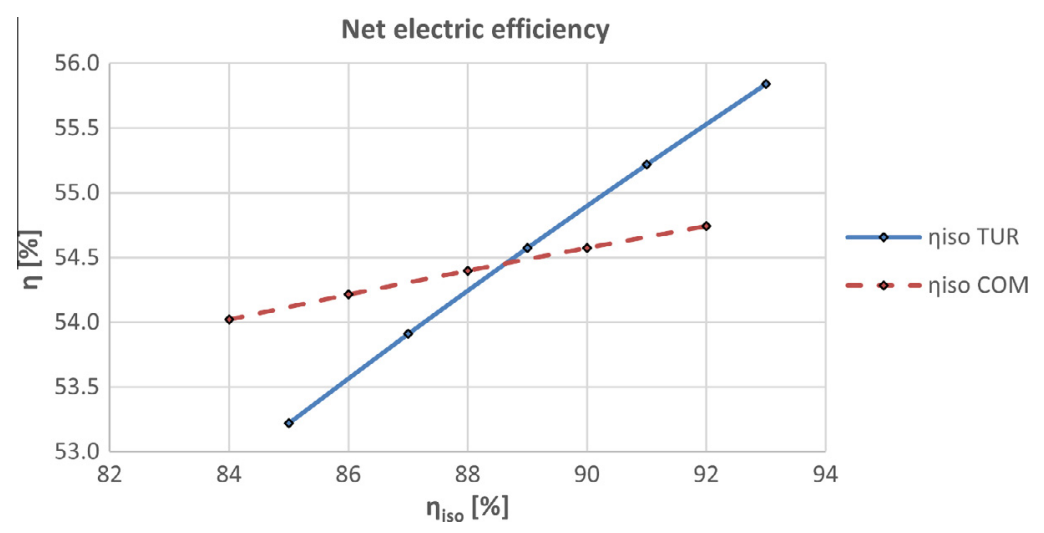

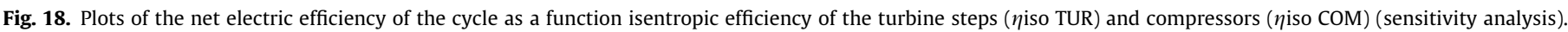

As reported in Table A- 6 of the supplementary online material and shown in Fig. 17 (plotting the power consumption of the two compression sections), the power consumption of the vapour phase compression increases considerably with the minimum cycle temperature. This has a considerable effect on the net electric efficiency, which decreases linearly by around 0.3 percentage points for each degree of increase of the minimum temperature. This value is considerably higher than that of combined cycles, which varies by 0.08 percentage point per degree, on the basis of the simulations made with the commercial software Thermoflex [33]. If cold cooling water is not available at the plant site and either a cooling tower or an air cooled condenser must be adopted, the performances of the NET Power cycle are appreciably affected compared to conventional combined cycles. This is the inherent limitation of supercritical $\mathrm{CO}_{2}$ cycles, as already described in [53].

\subsection{Sensitivity to isentropic efficiency of turbine and compressor}

In this section the effects of the expander efficiency on cycle performance are analysed. Five different values of turbine stage isentropic efficiency are considered: $85 \%, 87 \%, 89 \%, 91 \%$ and $93 \%$. The results are detailed in Table A-7 of the supplementary online material and summarized in Fig. 18.

The turbine isentropic efficiency has a huge effect on the net electric efficiency of the cycle and it is almost linearly correlated with it, as shown in Fig. 18. On average, the increase of a percentage point of the isentropic efficiency of the turbine stages causes an increase of the overall electric efficiency of 0.33 percentage points. It is interesting to compare this result with that found for a conventional gas turbine cycle, whose increase of electric efficiency would be greater than one percentage point [54]. The reason of such a reduced effect of the turbine efficiency on the cycle performance is the regenerative configuration of the NET Power cycle: the increase of turbine efficiency is partly compensated by the reduction of the heat available for preheating the cold streams in the regenerator.

Also the effect of the compressor isentropic efficiency on the cycle performance is limited. Five different values of compressor group isentropic efficiency have been considered: $84 \%, 86 \%, 88 \%$, $90 \%$ and $92 \%$ and the simulation of the cycle has been repeated. Results are reported in Table A-8 of the supplementary online material and represented in Fig. 18. The increase of one percentage point of compressor isentropic efficiency results in a net electric efficiency rise of only 0.09 percentage points. In a conventional gas turbine cycle, an increase of the isentropic efficiency of the compressor of one percentage point raises the overall gas turbine efficiency by one percentage point [54]. This impact is approximately one order of magnitude larger than the one found for the
NET Power cycle. The reasons of this great advantage of the NET Power cycle on the standard gas cycle is the saving of compression power due to the real gas effect of the $\mathrm{CO}_{2}$-rich mixture [53].

The fact that cycle efficiency is less affected by the performance of the turbomachines compared to a conventional gas turbine cycle indicates the opportunity of using the NET Power cycle also for small scale plants featuring turbine stages with limited efficiency.

\subsection{Effect of the ASU power consumption}

Only a few public references are available on the power consumption of cryogenic air separation units supplying high pressure oxygen (>50 bar) with $99.5 \%$ purity (i.e., $[21,31,40]$ ). Besides, there is also a large variation of data available in literature (e.g., 158 $\mathrm{kWh} / \mathrm{t}$ for $\mathrm{O}_{2}$ at atmospheric pressure and purity of 95\% [55], 515 $\mathrm{kWh} / \mathrm{t}$ for $\mathrm{O}_{2}$ at 8.6 bar and purity of 95\% [56]). Therefore, it is worth assessing the influence of the ASU consumption on the efficiency of the NET Power cycle by performing a sensitivity analysis. Fig. 19 plots the net electric efficiency of the NET Power cycle (the one described in Section 4) as a function of the specific power consumption of the ASU (expressed in $\mathrm{kJ} / \mathrm{kg}$ ). The two extreme points of the plot correspond to the specific consumption figures reported respectively in Refs. [55,56] for cryogenic ASUs supplying $95 \%$ purity $\mathrm{O}_{2}$ with delivery pressure increased to 120 bar (the specific power consumption was accordingly increased by adding an intercooled oxygen compressor). It is worth noting that, compared to ASU scheme considered in [40] and taken as reference in this study, the processes studied in $[55,56]$ are not optimized for delivering $\mathrm{O}_{2}$ at high pressure ( $>100$ bar): both schemes pres-surize gaseous $\mathrm{O}_{2}$ and not liquid $\mathrm{O}_{2}$, with a resulting penalty in the overall energy consumption of the ASU.

Fig. 19 clearly indicates that the performance of the ASU has a high weight on the efficiency of the NET Power cycle, leading to potential efficiency variations up to 4 percentage points. Thus, particular attention must be paid to the selection of the ASU scheme and its optimization for limiting the power consumption while providing high pressure, high purity oxygen, as well as high temperature heat to the regenerator.

\subsection{Effect of the thermodynamic property model adopted}

In this section the impact of fluid properties estimate on NET Power cycle performance is evaluated by comparing the results of the three different Equations of States already discussed in Sec-tion 3.4: PR, SRK and BWR-LS. The default binary parameters, retrieved from the Aspen Plus V8.4 databank, are adopted for the three equation of states. Detailed results are reported in Table A-9 of the supplementary online material. Depending on the EoS 


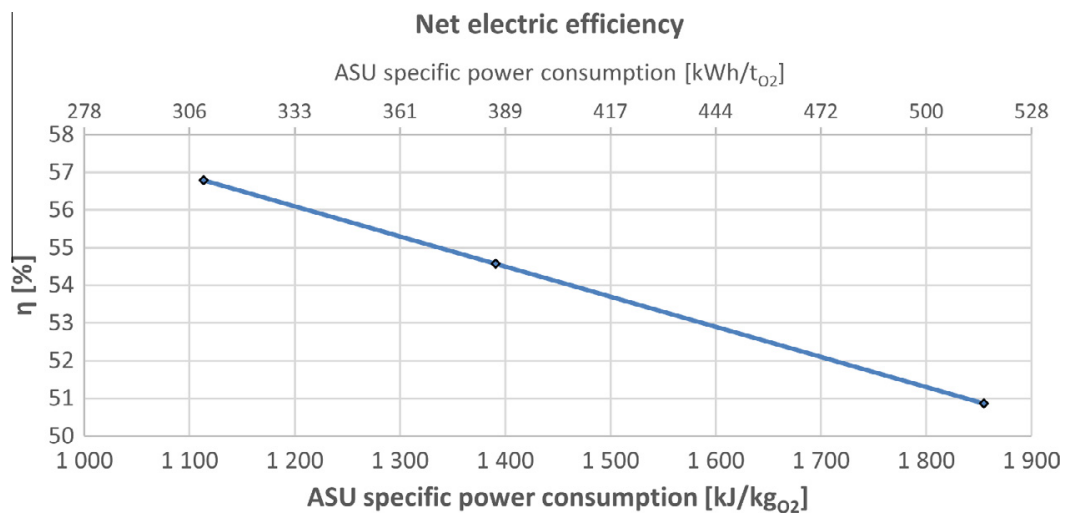

Fig. 19. Plots of the net electric efficiency of the cycle as a function ASU specific consumption (sensitivity analysis).

selected, the cycle efficiency varies between $54.58 \%$ (for EoS PR) and $55.22 \%$ (for EoS BWR-LS). Table A-9 of the supplementary online material compares also the consumption of the recycle compressors, highlighting how PR and SRK provide very similar estimates, whereas BWR-LS predicts a consumption about $5.8 \%$ lower, probably as a result of the higher estimate of the density of the dense phase streams. Even though the effect of the thermodynamic model is not negligible (0.64 percentage points), all the considered equations of states confirm the remarkable efficiency achievable by the cycle.

In the following sections, the Peng Robison equation of state will be considered for the optimization tasks. The Peng Robinson equations of state has been selected because of the reasons listed in Section 3.4.

\section{Cycle optimization}

The optimal operative conditions of the cycle (i.e., pressures, temperatures and mass flow rates) cannot be identified just with a sensitivity analysis, due to their mutual interaction. In order to address this issue, a systematic optimization has to be performed by means of a numerical optimization algorithm.

The objective function of the analysis is the net electric efficiency of the cycle, whereas the independent decision variables are the following:

- Turbine inlet pressure.

- Turbine outlet pressure.

- Flow rate of the recycle stream used to limit the combustor temperature (stream RE-4 in Fig. 6; this variable influences the combustor outlet temperature).

- Pressure ratios of the first three compression steps.

The (nonlinear) constraints of the optimization problem are the following:

- The outlet pressure of each compression stage must be always higher than the inlet pressure.

- The minimum temperature difference at the hot end of the regenerator should be greater or at least equal to $20^{\circ} \mathrm{C}$.

- The minimum temperature difference at the low temperature section of the regenerator should be greater or at least equal to $5{ }^{\circ} \mathrm{C}$.

In addition, lower and upper bounds on the optimization variables are set on the basis of physical and technological limitations.

The cycle optimization problem is tackled with the black-box approach [57]: a derivative-free optimization algorithm explores the solution space of independent decision variables and, for each sampled solution, the process simulation software (Aspen Plus) calculates the cycle and returns as output its performance. In other words, the process simulation software works as a black-box function called each time by the optimization algorithm to calculate the performance of the cycle. Compared to the equation oriented approach [57], such a black-box strategy may considerably increase the probability of determining the global optimum because the optimization level considers only the independent decision variables (a few ones) and design specification con-straints, since all the dependent variables (e.g., stream properties) and equipment equations (e.g., energy and mass balance equa-tions) are hidden into the process simulation model (black-box). On the other hand, the process simulation may fail to reach conver-gence or crash for some combinations of the input variables. More-over, the output of the process simulation model may be non-smooth (nondifferentiable or discontinuous) and noisy. Non-smoothness is typically caused by if/else or $\mathrm{max} / \mathrm{min}$ statements within the models of the equipment units or the activation of pinch points within the heat exchangers (such as the regenerator). Numerical noise is instead due to the finite convergence tolerance of the numerical algorithms used to solve the process simulation.

Due to the possible process simulation failures, function nonsmoothness and numerical noise, a derivative-free optimization method suitable for non-smooth black-box problems must be adopted. Among the available methods, PGS-COM, the hybrid derivative-free algorithm proposed by Martelli and Amaldi [58], was selected because of its superiority on constrained nonsmooth black-box problems. This algorithm combines the positive features of the CPSO (constant particle swarm optimizer) [59], GSS (generating set search) [60], and Complex [61].

Each iteration of the algorithm consists of three steps:

1. A search step corresponding to a population update of a revised CPSO.

2. An optional poll step corresponding to an iteration of the GSS around the best solution found so far.

3. A few optional reflection steps corresponding to a few iterations of the Complex algorithm.

Further details about the algorithm can be found in [58]. The algorithm is also coded for parallel computing as the function evaluations performed by the CPSO and GSS steps can be parallelized taking advantage of multiple core computers. The computational results presented in [58] indicate that for noisy non-smooth black-box problems PGS-COM performs better than eleven adhoc methods. As far as the setup parameters of the algorithm are concerned (e.g., number of swarm particles, neighbourhood size, 


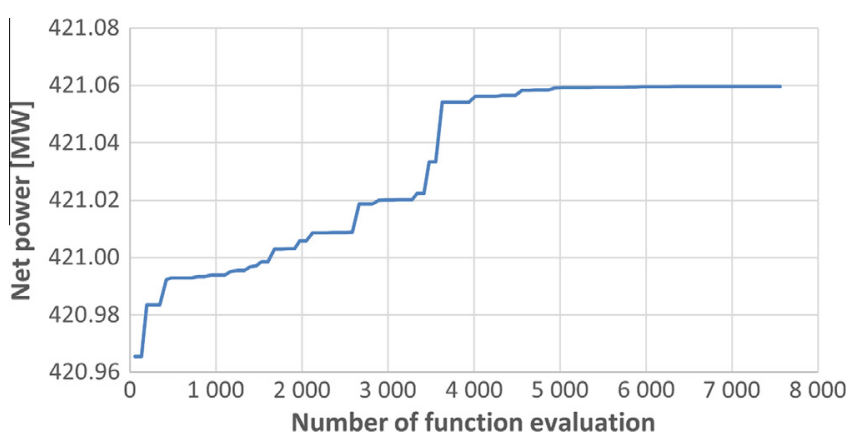

Fig. 20. Convergence curve of the PGS-COM optimization algorithm: value of the net electric power (objective function to be maximized) as a function of the number of function evaluations.

minimum GSS step size parameter, etc.), in this work we have adopted the same values recommended by the authors in [58]. The nonlinear constraints have been handled with the extreme barrier approach (i.e., if one of them is violated, the efficiency of the cycle is set to zero). The maximum number of function evalu-ations (i.e., number of cycle simulations) has been adopted as stop-ping criterion. Preliminary computational results have shown that after about 5000 function evaluations the improvement of the objective function was negligible (see for example Fig. 20), indicat-ing the convergence of the optimization algorithm to the optimal solution. Thus, the number of function evaluations was set to 7500 to have a sufficient safety margin. Each optimization was repeated five times taking the best solution out of the five runs so as to take into account the stochastic nature of the algorithm and minimize the risk of considering sub-optimal solutions (e.g., local optima).

\subsection{Optimization of cycle efficiency}

This optimization aims at determining the cycle design featuring the maximum efficiency without considering any constraint on the maximum temperature and pressure allowed in the regenerator. Such a design is called OPT in the following. The ranges investigated for the variables are reported below (note that the fuel thermal power is always kept equal to $768 \mathrm{MW}_{\mathrm{LHV}}$ ):

1. Turbine inlet pressure: between 200 bar and 400 bar.

2. Turbine outlet pressure: between 20 bar and 60 bar.

3. Combustor recycle flow rate: between $200 \mathrm{~kg} / \mathrm{s}$ and $1000 \mathrm{~kg} / \mathrm{s}$.

4. Pressure ratios of the first three compression steps: between 1 and 2.25 .

The maximum number of function evaluations was set to 7500 and the evolution of the objective function during an optimization run is shown in Fig. 20.

Table 10 compares the main performances and the operative conditions of the Base Case and of the maximum efficiency cycle. Compared to Base Case cycle, the optimized cycle features a lower turbine inlet pressure ( $-16.4 \mathrm{bar})$, a higher turbine discharge pressure (+13.1 bar), a lower combustor outlet temperature $(-26.2 \circ$ C) and lower pressure ratios of the compressors with dif-ferent distribution. This optimized combination of variables allows to increase the net electrical power output of $1.75 \mathrm{MW}$, corresponding to an increase of net electric efficiency of 0.22 percentage points. The higher turbine discharge pressure allows to save power consumption of the recycle compressors thanks to the positive effect on the $\mathrm{CO}_{2}$ density. Instead, the lower combustor outlet temperature (higher recycle flow rate) allows to achieve a perfect heat integration in the regenerator, where all the temperature differences are at the lower bound:
Table 10

Key performance results of the maximum efficiency cycle (OPT).

\begin{tabular}{|c|c|c|c|}
\hline & Unit & OPT & Base Case \\
\hline \multicolumn{4}{|l|}{ Independent optimization variables } \\
\hline Turbine inlet pressure & bar & 283.62 & 300 \\
\hline Turbine outlet pressure & bar & 47.153 & 34 \\
\hline Combustor recycle flow rate & $\mathrm{kg} / \mathrm{s}$ & 886.04 & 641.92 \\
\hline First compressor pressure ratio & & 1.255 & 1.380 \\
\hline Second compressor pressure ratio & & 1.190 & 1.297 \\
\hline Third compressor pressure ratio & & 1.153 & 1.202 \\
\hline \multicolumn{4}{|l|}{ Performance indexes } \\
\hline Thermal energy of feedstock (LHV) & $\mathrm{MW}_{\text {th }}$ & 768.31 & 768.31 \\
\hline Turbine power output & $\mathrm{MW}_{\mathrm{e}}$ & 609.74 & 622.42 \\
\hline Recycle gas compressors consumption & $\mathrm{MW}_{\mathrm{e}}$ & 97.81 & 111.15 \\
\hline Net electrical power output & $\mathrm{MW}_{\mathrm{e}}$ & 421.06 & 419.31 \\
\hline Net specific work ${ }^{\mathrm{a}}$ & $\mathrm{kJ} / \mathrm{kg}$ & 278.16 & 329.91 \\
\hline Net electrical efficiency (LHV) & $\%$ & 54.80 & 54.58 \\
\hline \multicolumn{4}{|l|}{ Dependent variables } \\
\hline Turbine pressure ratio & & 6.015 & 8.835 \\
\hline Combustor outlet temperature & ${ }^{\circ} \mathrm{C}$ & 1123.79 & 1150 \\
\hline Turbine outlet temperature & ${ }^{\circ} \mathrm{C}$ & 783.81 & 741.2 \\
\hline Cooling flow final temperature & ${ }^{\circ} \mathrm{C}$ & 162.95 & 181.94 \\
\hline Turbine inlet flow rate & $\mathrm{kg} / \mathrm{s}$ & 1513.7 & 1271 \\
\hline Cooling flow rate & $\mathrm{kg} / \mathrm{s}$ & 96.9 & 99.4 \\
\hline Total recycle flow rate & $\mathrm{kg} / \mathrm{s}$ & 1532.7 & 1292.4 \\
\hline
\end{tabular}

a Net electric power output/turbine inlet mass flow rate.

1. The cold-side temperature difference is $5{ }^{\circ} \mathrm{C}$.

2. The pinch point temperature difference occurring within the regenerator at the dew point of the exhaust gases is $5{ }^{\circ} \mathrm{C}$.

3. The hot-side temperature difference between flue gases and recycled streams is $20^{\circ} \mathrm{C}$ (minimum allowed value).

It is worth noticing that, although the improvement of the net electric efficiency is limited to only 0.22 percentage points (because the Base Case cycle features the same cycle variables as [21] which are quite good), there is a considerable difference in the operating conditions (pressures and temperatures) and in the mass flow rates between the Base Case and the optimized case. Besides, it is interesting to note that the optimized case (with max-imum efficiency) features operating conditions less aggressive and challenging for the combustor and turbine than the Base Case. This result has led the authors to explore solutions with less aggressive cycle variables and close-to-optimal efficiency, as described in the following sections.

\subsection{Optimized cycles with reduced turbine outlet temperature and turbine inlet pressure}

In this Section we want to assess the performance of optimized cycles with limited turbine outlet temperature and limited combustor pressure. The objective is to identify cycle designs with operating conditions less demanding for the three key components: regenerator, combustor and turbine. Indeed, the lower is the turbine outlet temperature and the lower is the thermo-mechanical requirement of the materials to be employed for the high temperature section of the regenerator. Similarly, a reduction of the turbine inlet pressure is beneficial for the combustor (high pressure causes not only thermo-mechanical stress but also fluid-dynamic issues of flame stability [25]), for the turbine and the regenerator. Therefore, the optimization of the cycle is repeated by considering progressively lower values of turbine out-let temperature and turbine inlet pressure. Table 11 reports the conditions and acronym of each case. The optimized case of the previous section is denoted as case OPT.

It is worth noting that when the TOT upper bound is reduced below $750{ }^{\circ} \mathrm{C}$, so as to use cheaper materials for the high tempera- 
Table 11

Optimized cases with reduced turbine outlet temperature and turbine inlet pressure.

\begin{tabular}{cllllll}
\hline \multirow{2}{*}{$\begin{array}{c}\mathrm{p} \max \\
\text { (bar) }\end{array}$} & \multicolumn{5}{c}{ TOT $\max \left({ }^{\circ} \mathrm{C}\right)$} \\
\cline { 2 - 6 } & 650 & 700 & 725 & 750 & 775 & T no limit \\
\hline \multirow{2}{*}{200} & P200- & P200- & P200- & P200- & P200- & OPT- \\
& T650 & T700 & T725 & T750 & T775 & 200 \\
250 & P250- & P250- & P250- & P250- & P250- & OPT- \\
& T650 & T700 & T725 & T750 & T775 & 250 \\
400 & POPT- & POPT- & POPT- & POPT- & POPT- & OPT \\
& T650 & T700 & T725 & T750 & T775 & \\
\hline
\end{tabular}

ture section of the regenerator, the heat recovery becomes suboptimal, and the temperature decrease of the streams entering the combustor causes a significant efficiency penalty.

When the turbine inlet pressure is reduced (cases at 200 and 250 bar), a modification of the range of the optimization variables is required in order to generate feasible solutions. Hence, the following bounds have been modified:
1. Turbine inlet pressure: 150 bar as lower bound and 250 bar or 200 bar as upper bound.

2. Turbine outlet pressure: between 10 bar and 60 bar.

The optimization results are reported in Tables A-10, A-11 and A-12 of the supplementary online material, while a summary of the main findings is shown in Figs. 21 and 22. It is worth noting that all the cycles reported in the two figures are optimized and feature combustor outlet temperatures in the range $1100-1200^{\circ} \mathrm{C}$.

As clearly indicated in Fig. 21, the cases with high TOT (higher than $725^{\circ} \mathrm{C}$ ) are not considerably influenced by the turbine inlet pressure which can vary between 250 and 300 bar without major efficiency penalty (for the same reasons already described in Section 5.3). Instead, the cases with limited TOT (lower than $725^{\circ} \mathrm{C}$ ) require increasingly high pressures, even up to $400 \mathrm{bar}$, to reach good efficiency values. If the turbine inlet pressure needs to be reduced to 200 bar for technological barriers, the maximum achievable efficiency is $53.23 \%$, i.e., 1.57 percentage points less than the optimized case without limits on the maximum TOT and pressure (case OPT)

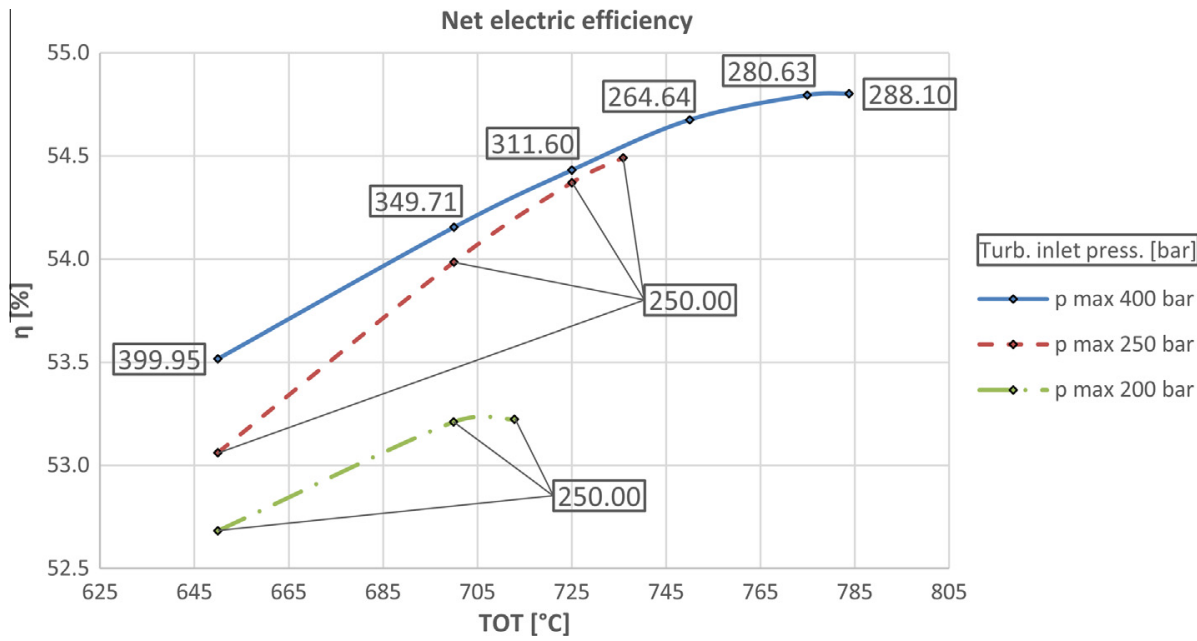

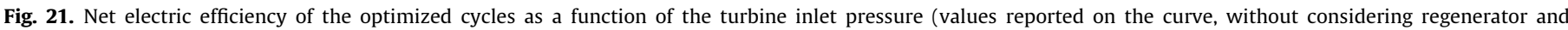
combustor pressure losses) and turbine outlet temperature (on the abscissa).

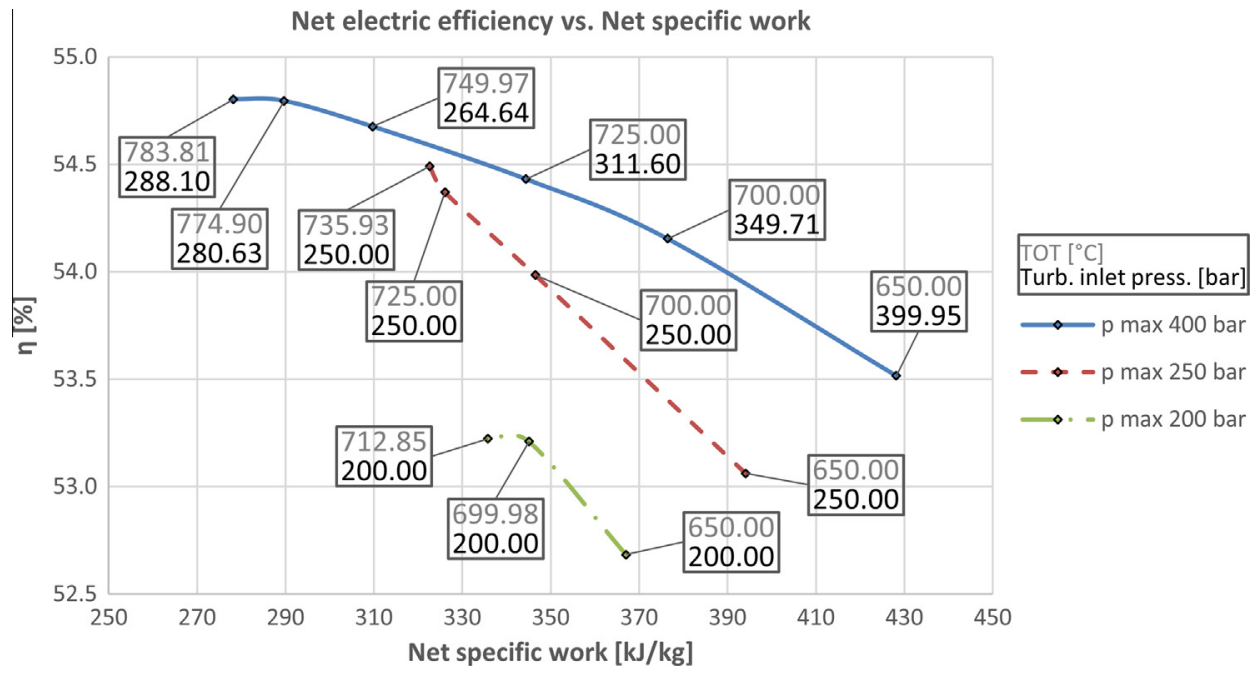

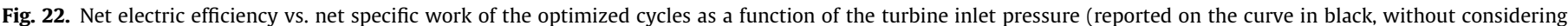

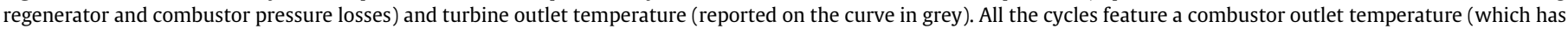
been optimized) between 1100 and $1200^{\circ} \mathrm{C}$. 
Fig. 22 shows the conflict between net efficiency and net specific work. The former is favoured by high turbine outlet temperatures (obtained by keeping low the turbine expansion ratio with low turbine inlet pressures and/or high turbine outlet pressures) which allow to preheat the recycle streams to higher temperatures and then save fuel input. The net specific work is instead favoured by high turbine expansion ratios (which lead to low turbine outlet temperatures) because the specific work of the turbine increases more than that of the compressor with the pressure ratio.

Among the cases reported in Fig. 22, the case with turbine inlet pressure equal to 250 bar and turbine outlet temperature equal to $725{ }^{\circ} \mathrm{C}$ appears to have the best compromise between efficiency, net specific work and cost of the required components. This case reaches a net electric efficiency of $54.37 \%$, only 0.43 percentage points lower than the optimal case, but a higher net specific work $(+40 \mathrm{~kJ} / \mathrm{kg}$, i.e., $15 \%$ higher than the maximum efficiency cycle) with appreciably lower temperature and pressure. Hence, despite being slightly sub-optimal from a thermodynamic point of view, this configuration looks interesting since (i) it features a lower specific investment cost ( $\$ / \mathrm{kW}$ of installed power) due to the higher net specific work, (ii) it allows to employ less expensive materials and/ or technological solutions for the most critical pieces of equipment.

\subsection{Optimized cycles with reduced heat transfer area of the regenerator}

Starting from the cycle featuring the maximum efficiency, the effect of the variation of the minimum temperature differences within the regenerator has been analysed with three optimization cases. The minimum temperature difference (occurring at the cold end of the regenerator and at the pinch point) has been gradually raised from $5{ }^{\circ} \mathrm{C}$ to $10^{\circ} \mathrm{C}$ with a step of $2.5^{\circ} \mathrm{C}$, while the hot end temperature difference has been increased from $20{ }^{\circ} \mathrm{C}$ to $40{ }^{\circ} \mathrm{C}$ with a step of $10^{\circ} \mathrm{C}$. The optimization variables and the most significant thermodynamic conditions of the cycle are shown in Table A-13 of the supplementary online material.

As shown in Fig. 23, an increase of the minimum temperature differences in the range investigated causes an efficiency reduction of 1.73 percentage points, but with a significant reduction of the heat transfer surface of the regenerator. The reduction of the heat transfer surface, and therefore of the cost of the regenerator, is a result of both an increase of the mean logarithmic temperature differences of the regenerator sections and a decrease of the heat transferred within the component. Indeed, the thermal power of the regenerator is $1521.92 \mathrm{MW}$ for the case with minimum temperature differences $5-20^{\circ} \mathrm{C}$ (i.e., $5^{\circ} \mathrm{C}$ at the cold end and pinch point, $20^{\circ} \mathrm{C}$ at the hot end), and it is reduced by $211.73 \mathrm{MW}$ with doubled temperature differences (i.e., case $10-40^{\circ} \mathrm{C}$ ). As a result,

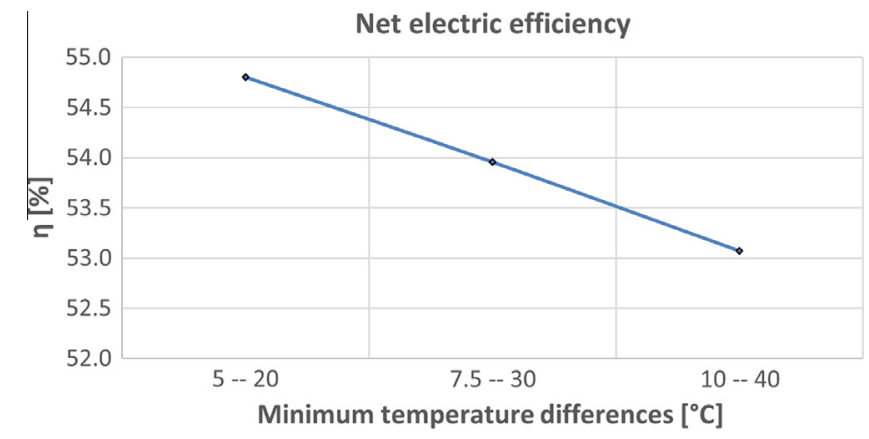

Fig. 23. Plot of the net electric efficiency of the optimized cycles as a function of the minimum heat transfer temperature differences in the regenerator. For example, 520 denotes the case with $5{ }^{\circ} \mathrm{C}$ temperature difference at the cold end and pinch point, and $20^{\circ} \mathrm{C}$ at the hot end of the regenerator.

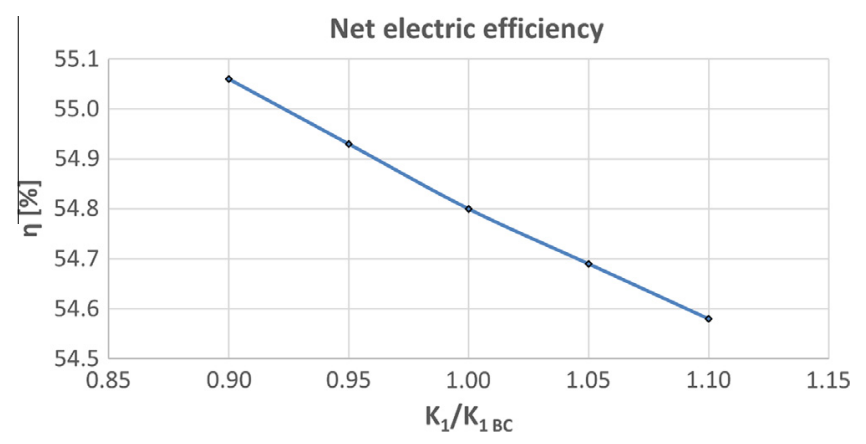

Fig. 24. Plot of the net electric efficiency of the optimized cycles as a function of the $K_{1}$ parameter of the turbine model (related to the effectiveness of the cooling system).

when the temperature differences are doubled, UA is halved (starting from $162.7 \mathrm{MW} / \mathrm{K}$ it is reduced to $81.0 \mathrm{MW} / \mathrm{K}$ ).

To optimize the trade-off between thermodynamic efficiency and costs caused by a variation of the temperature differences in the regenerator, a techno-economic optimization would be worth performing, if a cost correlation of the regenerator were available. However, being an unconventional piece of equipment such cost data are not publicly available yet.

\subsection{Optimized cases for different effectiveness of the turbine cooling system}

As already pointed out, the effectiveness of the turbine blades cooling system has a great influence on the performance of the NET Power cycle. However, the turbine model presented in Sec-tion 3.1 has been calibrated on the basis of the typical cooling tech-nology of Natural Gas fired gas turbines. Therefore, this model may either over- or under-estimate the cooling flow rate required by the expander of the NET Power cycle. Moreover, the effectiveness of expander cooling systems is steadily increasing over time, as a result of technological advancements, and it is therefore worth assessing the benefit of such an improvement on the performance of the NET Power cycle. For this reason, the optimization of the whole cycle has been carried out considering four different values of the parameter $K_{1}$ at the basis of the turbine model (see Sec-tion 3.1.2), which is the one directly linked to the blade cooling effectiveness. In the sensitivity analysis, two better and two worse scenarios are considered by varying the parameter $K_{1}$ of $\pm 5 \%$ and \pm 10 \% (starting from the calibrated value reported in Section 3.1.2).

The net electric efficiency trend is shown in Fig. 24, whereas the optimized variables and performance results are shown in Table A-14 of the supplementary online material. The trend is almost linear and the efficiency variation in the range analysed is \pm 0.25 percent-age points.

\section{Conclusions}

This paper describes the modelling, thermodynamic analysis and optimization of the NET Power cycle, performed by developing accurate Aspen Plus models of the equipment units and by using a suitable optimization algorithm.

The Base Case design, featuring the same cycle variables as the one benchmarked in the recent IEA report [21], has a net electric efficiency of $54.58 \%$. The difference of -0.47 percentage point with respect to the value calculated in [21] is likely due to more conservative assumptions on the regenerator pinch point temperature difference and on the efficiency of the compressor/pump. The difference of -4.32 percentage with respect to the efficiency value claimed by cycle developers in [15] appears to be due to the turbine cooling system (i.e., cooling flows and the related losses) 
which was not probably taken into account in the calculations reported in [15].

The cycle optimized for the maximum efficiency features a turbine inlet pressure of 283.62 bar, a turbine outlet pressure of $47.15 \mathrm{bar}$, a combustor outlet temperature of $1123.79^{\circ} \mathrm{C}$. The net electric efficiency is $54.80 \%, 0.22$ percentage points higher than the Base Case design, and the net specific work is $278.16 \mathrm{~kJ} / \mathrm{kg}$.

The sensitivity analyses have shown that:

(i) Differently from gas turbine cycles, even if state-of-the-art blade cooling and material are adopted for the turbine, the NET Power cycle reaches the optimal net electric efficiency at a rather low turbine inlet temperature (or combustor outlet temperature), in the range between $1100^{\circ} \mathrm{C}$ and $1200^{\circ} \mathrm{C}$. The main responsible of this unusual efficiency trend appears to be the considerable increase of the turbine cooling flow rates.

(ii) There exist an optimal range for the turbine inlet pressure, between 260 and 300 bar, where the cycle efficiency remains close to maximum because of the compensation effect of the regenerator (which allows to balance the decrease of net specific work occurring at low inlet pressures with an increase of the recovered heat). This finding is important as it notices the possibility of adopting turbine inlet pressure limited to 260 bar without major efficiency penalty. It is worth noting that keeping low the turbine inlet pressure is not only advantageous for the mechanical stress of the cycle components (combustor, turbine and regenerator) but also to mitigate the flame stability issues occurring at high pressures.

(iii) Below 240 bar of turbine inlet pressure, the cycle efficiency drastically drops down as a result of the suboptimal heat integration in the regenerator. If the turbine inlet pressure is limited to 200 bar, the efficiency drops by 1.5 percentage points, even if all the other cycle variables are optimized.

(iv) If the turbine outlet temperature must be maintained below $725^{\circ} \mathrm{C}$ to use less costly material in the regenerator, increasingly high turbine inlet pressures must be chosen to maximize the net electric efficiency. The lower is the allowed turbine outlet temperature and the higher is the effect of the inlet pressure on the cycle efficiency, reaching 400 bar if the TOT is limited to $650{ }^{\circ} \mathrm{C}$.

(v) The cooling water temperature has a considerable impact on cycle performance, about triple compared to a combined cycle. An increase of $9{ }^{\circ} \mathrm{C}$ causes an efficiency decrease of 2.44 percentage points (from $56.16 \%$ to $53.72 \%$ ). This is an important limitation of the NET Power cycle which makes it less attractive for sites lacking cold cooling water.

(vi) Although the effect of the accuracy of the equation of state on the calculated cycle efficiency is not negligible ( 0.64 percentage points), all the considered equations of states confirm the remarkable efficiency achievable by the cycle.

As far as the effect of the performance of the equipment units is concerned, the following conclusions can be drawn:

(i) The regenerator is the most critical component of the cycle, due to the huge amount of thermal power to be recovered in order to maximize the cycle efficiency. The increase of the pinch point temperature difference of the regenerator leads to a considerable saving of heat transfer area (i.e., UA is halved when the pinch point temperature differences are doubled) but also to an appreciable loss of cycle efficiency, which reaches up to 3 percentage points when minimum $\Delta T$ are doubled compared to the Base Case (corresponding to an efficiency of $51.39 \%$ ). (ii) The performance of the ASU has a high weight on the efficiency of the NET Power cycle, leading to potential efficiency variations up to 4 percentage points. Thus, particular attention must be paid to the selection of the ASU scheme and its optimization for limiting the power consumption while providing high pressure high purity oxygen as well as high temperature heat to the regenerator.

(iii) A variation of the isentropic efficiency of compressor and turbine has a much lower $(0.33$ percentage points per each percentage point variation of the isentropic efficiency for the turbine and 0.09 percentage points per each percentage point variation for the compressor) impact on NET Power cycle performance than experienced in conventional gas turbines. The fact that cycle efficiency is not considerably affected by the performance of the turbomachines indicates the opportunity of using the NET Power cycle also for small scale plants featuring turbine stages with limited efficiency.

(iv) In the development of the turbine, particular attention should be paid to the effectiveness of the blade cooling system due to the large efficiency penalty caused by the cooling flows.

Among the optimized cases, it is worth noticing the solution with a turbine inlet pressure of 250 bar and a turbine outlet temperature of $725^{\circ} \mathrm{C}$. This case reaches a net electric efficiency of $54.37 \%$, only 0.43 percentage points lower than the optimal case, but a higher net specific work $(+40 \mathrm{~kJ} / \mathrm{kg}$, i.e., $15 \%$ higher than the maximum efficiency cycle) with appreciably lower temperature and pressure. Hence, despite being slightly sub-optimal from a thermodynamic point of view, this configuration looks interesting since (i) it features a lower specific investment cost $(\$ / \mathrm{kW}$ of installed power) due to the higher net specific work, (ii) it allows the adoption of less expensive materials and/or technological solutions for the most critical pieces of equipment.

In summary, the NET Power cycle looks an interesting solution to achieve very high electric efficiencies from natural gas combustion with nearly zero $\mathrm{CO}_{2}$ emissions. However, the authors think that research and development efforts are still needed and must involve the following activities:

- To perform a detailed engineering study and cost evaluation of the regenerator, which is the most critical and, probably, expensive piece of equipment. This would allow also to perform a techno-economic optimization of the cycle aimed at minimizing the cost of electricity.

- To conduct an experimental assessment of the minimum excess of oxygen required to properly operate (i.e., without affecting the combustion flame stability) the high pressure combustor. It is crucial to address this issue since the amount of oxygen in excess affects not only the size and power consumption of the ASU, but also the purity of the stream of captured $\mathrm{CO}_{2}$.

- To calibrate a suitable Equation of State on the basis of relevant experimental data (same mixture compositions, temperature and pressure ranges of the cycle), in order to accurately design the main pieces of equipment of the cycle (compressors, heat exchangers, etc.).

\section{Acknowledgements}

The authors acknowledge LEAP (Laboratorio Energia Ambiente Piacenza) for funding the research activity of Roberto Scaccabarozzi, and Prof. Paolo Chiesa (Politecnico di Milano) for the gas turbine data used to calibrate the cooled expander model. 


\section{Appendix A. Supplementary material}

Supplementary data associated with this article can be found, in the online version, at http://dx.doi.org/10.1016/j.apenergy.2016. 06.060 .

\section{References}

[1] Kyle A, Black J, Woods M, Kuehn N, Shelton W, Yang W-C. Carbon capture approaches for natural gas combined cycle systems; 2010.

[2] Finkenrath M. Cost and performance of carbon dioxide capture from power generation. IEA working paper; 2011.

[3] Bolland O, Mathieu P. Comparison of two $\mathrm{CO}_{2}$ removal options in combined cycle power plants. Energy Convers Manage 1998;39(16-18):1653-63.

[4] Iantovski E, Mathieu P. Highly efficient zero emission $\mathrm{CO}_{2}$-based power plant. Energy Convers Manage 1997;38(Suppl.):S141-6.

[5] Allam RJ, Palmer MR, Brown GW. System and method for high efficiency power generation using a carbon dioxide circulating working fluid. Patent US 12/ 872,777; 2011

[6] Allam RJ, Palmer MR, Brown GW, Fetvedt JE, Forrest BA. System and method for high efficiency power generation using a carbon dioxide circulating working fluid. Patent US 13/843,313; 2013

[7] Jericha H, Sanz W, Göttlich E. Design concept for large output Graz cycle gas turbines. J Eng Gas Turbines Power 2007;130(1):011701.

[8] Bannister RL, Newby RA, Yang W-C. Final report on the development of a hydrogen-fueled combustion turbine cycle for power generation. J Eng Gas Turbines Power 1999;121(1):38-45.

[9] Chiesa P, Lozza G. $\mathrm{CO}_{2}$ emission abatement in IGCC power plants by semiclosed cycles: Part A-with oxygen-blown combustion. J Eng Gas Turbines Power 1999;121(4):635-41.

[10] Lozza G, Chiesa P, Romano MC, Valenti G. $\mathrm{CO}_{2}$ capture from natural gas combined cycles. In: 1st International congress "Sustainable Fossil Fuel for Future Energy - S4FE"; 2009. p. 1-8.

[11] Riethmann T, Sander F, Span R. Modelling of a supercharged semi-closed oxyfuel combined cycle with $\mathrm{CO}_{2}$ capture and analysis of the part-load behavior. Energy Proc Feb. 2009;1(1):415-22.

[12] Yantovski EI, Zvagolsky KN, Gavrilenko VA. The COOPERATE-demo power cycle. Energy Convers Manage Jun. 1995;36(6-9):861-4.

[13] Yantovski EI. Stack downward: zero emission fuel-fired power plants concept. Energy Convers Manage 1996;37(6-8):867-77.

[14] Mathieu P, Nihart R. Sensitivity analysis of the MATIANT cycle. Energy Convers Manage Oct. 1999;40(15-16):1687-700.

[15] Allam RJ, Palmer MR, Brown GW, Fetvedt JE, Freed DA, Nomoto H, et al. High efficiency and low cost of electricity generation from fossil fuels while eliminating atmospheric emissions, including carbon dioxide. Energy Proc 2013;37:1135-49.

[16] Allam RJ, Fetvedt JE, Forrest BA, Freed DA. The oxy-fuel, supercritical $\mathrm{CO}_{2}$ Allam cycle: new cycle developments to produce even lower-cost electricity from fossil fuels without atmospheric emissions. In: ASME turbo expo 2014: turbine technical conference and exposition; 2014. p. V03BT36A016.

[17] Sanz W, Jericha H, Moser M, Heitmeir F. Thermodynamic and economic investigation of an improved Graz cycle power plant for $\mathrm{CO}_{2}$ capture. J Eng Gas Turbines Power 2005;127(4):765-72.

[18] Jericha H, Sanz W, Göttlich E, Neumayer F. Design details of a 600 MW Graz cycle thermal power plant for $\mathrm{CO}_{2}$ capture. In: ASME turbo expo 2008: power for land, sea and air. p. 507-16.

[19] Anderson RE, MacAdam S, Viteri FV, Davies DO, Downs JP, Paliszewski A, et al. Adapting gas turbines to zero emission oxy-fuel power plants. In: ASME turbo expo 2008: power for land, sea and air. p. 781-91.

[20] Hustad C-W, Tronstad I, Anderson RE, Pronske KL, Viteri FV. Optimization of thermodynamically efficient $40 \mathrm{MW}$ zero emission pilot and demonstration power plant in Norway. In: ASME turbo expo 2005: power for land, sea, and air. p. 271-8.

[21] Mancuso L, Ferrari N, Chiesa P, Martelli E, Romano MC. Oxy-combustion turbine power plants. IEAGHG report 2015/05, August, 2015.

[22] NET Power website, news section: <https://netpower.com/news-posts/shawand-exelon-join-net-power-to-develop-next-generation-power-technology/> [Retrieved May 16, 2016].

[23] El-Masri MA. On thermodynamics of gas-turbine cycles: Part 2-a model for expansion in cooled turbines. J Eng Gas Turbines Power 1986;108(1):151-9.

[24] Toshiba Corporation website, Newsroom: <http://news.toshiba.com/pressrelease/corporate/toshiba-supplies-first-kind-supercritical-co2-turbine-newthermal-power-gene/> [Retrieved May 16, 2016].

[25] Kobayashi H, Tamura T, Maruta K, Niioka T, Williams FA. Burning velocity of turbulent premixed flames in a high-pressure environment. Symp Combust 1996;26(1):389-96.

[26] NET Power website, news section: <http://www.netpower.com/newsposts/toshiba-announces-successful-operation-of-novel-combustor-used-innet-power-system/>. [Retrieved May 16, 2016].

[27] Toshiba Corporation website, Newsroom: <https://www.toshiba.co.jp/ about/press/2013_08/pr0101.htm\#PRESS/>. [Retrieved May 16, 2016].

[28] Liu CY, Chen G, Sipöcz N, Assadi M, Bai XS. Characteristics of oxy-fuel combustion in gas turbines. Appl Energy Jan. 2012;89(1):387-94.
[29] Manenti F, Rossi F, Croce G, Grottoli MG, Altavilla M. Intensifying air separation units. Chem Eng Trans 2013;35:1249-54.

[30] Martelli E, Kreutz TG, Carbo M, Consonni S, Jansen D. Shell coal IGCCS with carbon capture: conventional gas quench vs. innovative configurations. Appl Energy 2011;88(11):3978-89.

[31] Liu G, Larson ED, Williams RH, Kreutz TG, Guo X. Making Fischer-Tropsch fuels and electricity from coal and biomass: performance and cost analysis. Energy Fuels 2011;25(1):415-37.

[32] Aspen Technology, Inc. website: <http://www.aspentech.com/>. [Retrieved May 16, 2016].

[33] Thermoflow Inc. website: <http://www.thermoflow.com/>. [Retrieved May 16 , 2016]

[34] GECOS - Group Energy COnversion Systems - Dipartimento di Energia Politecnico di Milano website: <http://www.gecos.polimi.it/> [Retrieved May $16,2016]$.

[35] Horlock JH, Watson DT, Jones TV. Limitations on gas turbine performance imposed by large turbine cooling flows. J Eng Gas Turbines Power 2001;123 (3):487-94.

[36] Chiesa P, Macchi E. A thermodynamic analysis of different options to break $60 \%$ electric efficiency in combined cycle power plants. J Eng Gas Turbines Power 2004:126(4):770-85.

[37] Poling BE, Prausnitz JM, O'Connell JP. The properties of gases and liquids. 5th ed. McGraw-Hill Companies, Inc.; 2001.

[38] Guo J. Design analysis of supercritical carbon dioxide recuperator. Appl Energy 2016;164:21-7.

[39] Kemp IC. Pinch analysis and process integration: a user guide on process integration for the efficient use of energy. 2nd ed. Elsevier Ltd.; 2007.

[40] Gibson SM. Oxygen plants for gasification. In: New horizons in gasification.

[41] Peng D-Y, Robinson DB. A new two-constant equation of state. Ind Eng Chem Fundam 1976;15(1):59-64.

[42] Soave G. Equilibrium constants from a modified Redlich-Kwong equation of state. Chem Eng Sci Jun. 1972;27(6):1197-203.

[43] Li H, Jakobsen JP, Wilhelmsen Ø, Yan J. PVTxy properties of $\mathrm{CO}_{2}$ mixtures relevant for $\mathrm{CO}_{2}$ capture, transport and storage: review of available experimental data and theoretical models. Appl Energy Nov. 2011;88 (11):3567-79.

44] Diamantonis NI, Boulougouris GC, Mansoor E, Tsangaris DM, Economou IG. Evaluation of cubic, SAFT, and PC-SAFT equations of state for the vapor-liquid equilibrium modeling of $\mathrm{CO}_{2}$ mixtures with other gases. Ind Eng Chem Res 2013;52(10):3933-42

[45] Mantovani M, Chiesa P, Valenti G, Gatti M, Consonni S. Supercritical pressuredensity-temperature measurements on $\mathrm{CO}_{2}-\mathrm{N}_{2}, \mathrm{CO}_{2}-\mathrm{O}_{2}$ and $\mathrm{CO}_{2}-\mathrm{Ar}$ binary mixtures. J Supercrit Fluids 2012;61:34-43.

[46] Fenghour A, Wakeham WA, Watson JTR. Densities of (water + methane) in the temperature range $430 \mathrm{~K}$ to $699 \mathrm{~K}$ and at pressures up to $30 \mathrm{MPa}$. J Chem Thermodyn Apr. 1996;28(4):447-58.

[47] Müller G, Bender E, Maurer G. Das Dampf-Flüssigkeitsgleichgewicht des ternären Systems Ammoniak-Kohlendioxid-Wasser bei hohen Wassergehalten im Bereich zwischen 373 und 473 Kelvin. Berichte der Bunsengesellschaft für Phys. Chemie 1988;92(2):148-60.

[48] Patel MR, Holste JC, Hall KR, Eubank PT. Thermophysical properties of gaseous carbon dioxide-water mixtures. Fluid Phase Equilib 1987;36:279-99.

[49] Li H, Yan J. Impacts of equations of state (EOS) and impurities on the volume calculation of $\mathrm{CO}_{2}$ mixtures in the applications of $\mathrm{CO}_{2}$ capture and storage (CCS) processes. Appl Energy Dec. 2009;86(12):2760-70.

[50] Stanger R, Wall T, Spörl R, Paneru M, Grathwohl S, Weidmann M, et al. Oxyfuel combustion for $\mathrm{CO}_{2}$ capture in power plants. Int J Greenh Gas Control 2015;40:55-125.

[51] Kvamsdal HM, Jordal K, Bolland O. A quantitative comparison of gas turbine cycles with $\mathrm{CO}_{2}$ capture. Energy 2007;32(1):10-24.

[52] Badran 00. Gas-turbine performance improvements. Appl Energy Sep. 1999;64(1-4):263-73.

[53] Angelino G. Real gas effects in carbon dioxide cycles. In: ASME 1969 gas turbine conference and products show. p. V001T01A071.

[54] Horlock JH. Advanced gas turbine cycles. 1st ed. Pergamon; 2003.

[55] Higginbotham P, White V, Fogash K, Guvelioglu G. Oxygen supply for oxyfuel $\mathrm{CO}_{2}$ capture. Int J Greenh Gas Control 2011;5(Suppl. 1):S194-203.

[56] Kuehn N, Haslback J, Lewis E, Pinkerton LL, Simpson J, Turner MJ, Varghese E, Woods M. Cost and performance baseline for fossil energy plants volume 1 : bituminous coal and natural gas to electricity. NETL report; 2013.

[57] Biegler LT, Grossmann IE, Westerberg AW. Systematic methods of chemical process design. 1st ed. New Jersey 07458: Upper Saddle River; 1997.

[58] Martelli E, Amaldi E. PGS-COM: a hybrid method for constrained non-smooth black-box optimization problems. Comput Chem Eng 2014;63:108-39.

[59] Hu Xiaohui, Eberhart R. Solving constrained nonlinear optimization problems with particle swarm optimization. In: 6th World multiconference on systemics, cybernetics and informatics 2002, prociding of 6th world multiconference on systemics, cybernetics and informatics.

[60] Lewis RM, Shepherd A, Torczon V. Implementing generating set search methods for linearly constrained minimization. SIAM J Sci Comput Jan. 2007;29(6):2507-30.

[61] Andersson J. Multiobjective optimization in engineering design: applications to fluid power systems Thesis No. 657. Linköping, Sweden: Linköping University; 2001. 